\title{
LISTA ACTUALIZADA DE LOS MAMÍFEROS DE MÉXICO GERARDOCEBALLOS ${ }^{1}$, JOAQUÍN ARROYO-CABRALES ${ }^{2}$, RODRIGO A. MEDELLÍN ${ }^{1}$ Y YOLANDA DOMÍNGUEZ-CASTELLANOS ${ }^{1}$
}

\author{
${ }^{1}$ Instituto de Ecología, UNAM, Ciudad Universitaria, Apartado Postal 70-275, 04510 \\ México,D.F., MÉXICO.e-mail: gceballo@miranda.ecologia.unam.mx \\ ${ }^{2}$ Laboratorio de Arqueozoología «M. en C. Ticul Álvarez Solórzano», Subdirección de \\ Laboratorios y Apoyo Académico, INAH, Moneda \# 16, Col. Centro, 06060 México, D. F., \\ México.
}

\begin{abstract}
Resumen: La megadiversidad de México es claramente ilustrada por el número de especies de mamíferos presentes en el territorio nacional. Este número ha variado en los últimos 8 años por los cambios taxonómicos y nomenclaturales, además del hallazgo de nuevas especies. Aquí se presenta un listado actualizado de los mamíferos nativos de México, tanto terrestres como acuáticos. Además se indica el estado de conservación de acuerdo con las autoridades federales o algunos organismos internacionales, la condición de insularidad, y la distribución original, ya sea en Norteamérica, Sudamérica, Mesoamérica o Endémica y sus combinaciones. En total, se documentan 529 especies nativas de 192 géneros, 47 familias y 12 órdenes.
\end{abstract}

Palabras clave: Mamíferos, México , composición , distribución , conservación.

Abstract: Mexican megadiversity is clearly illustrated by the number of mammals found in its territory. The species number has changed in the past 8 years due to taxonomical and nomenclatural changes, as well as the finding of new species occurring in the country. An upto-date list of the native mammals from México, both terrestrial and marine, is provided, including data on their conservation status in accordance to federal or international regulations; the presence of island populations; and the origen affinities, either North American, South American, Mesoamerican, or Endemic. Overally, there are 529 Mexican native species pertaining to 193 genera, 47 families, and 12 orders.

Keywords: Mammals, México, composition, distribution, conservation.

Se conoce bien que México está entre los países más biodiversos en el mundo. En aproximadamente $1.6 \%$ de la superficie de tierras emergidas, mantiene aproximadamente 10\% de las especies vivientes (Ceballos y Navarro, 1991; Ceballos y Brown, 1995; Mittermeier y Goettsch de M., 1992; Mittermeier et al., 1997). Aunque en los últimos años varios autores han compilado listados de mamíferos mexicanos terrestres y marinos (Arita y Ceballos, 1997; Aurioles, 1993; Ceballos y Oliva, 2005; Ceballos et al., 2002; Cervantes et al., 1994; Ramírez-Pulido et al., 1983, 1986, 1996; Salinas y Ladrón 
de Guevara, 1993; Torres et al., 1995), recientemente ha habido muchos cambios taxonómicos, descripciones de nuevas especies y nuevos registros de especies, lo que ha aumentado el inventario de mamíferos del país significativamente. En este trabajo se presenta una lista actualizada completa de la mastofauna de México como se conoce hasta el presente, se identifican sus principales afinidades y procedencia de las especies, así como la endemicidad, insularidad y, estado de conservación de cada una de las especies. Finalmente, se incorpora una sección donde se discute de las especies introducidas que se han establecido en México. Al actualizar la lista de especies mexicanas de mamíferos, esperamos proporcionar una base que estimule el estudio adicional y detallado de los mamíferos de nuestro país e incite la investigación por los investigadores nacionales y extranjeros.

\section{MÉTODOS}

Para compilar la nueva lista, se usaron como punto de partida las listas de los trabajos de Ceballos y Oliva (2005) y Ramírez Pulido et al. (2005) completándolos con referencias adicionales que se señalan adelante. Se excluyeron los roedores múridos introducidos (Mus musculus, Rattus norvegicus y R. rattus) y las especies domésticas con poblaciones silvestres, como los perros, gatos, cabras y asnos. Nuestra nomenclatura sigue la propuesta por Wilson y Reeder (2005), con algunas excepciones que se señalan en el texto. En este texto se han incorporado los cambios tatonómicos a nivel de orden y familia, que son muy diferentes a los tratados en nuestros trabajos previos (Arita y Ceballos, 1997; Ceballos y Oliva, 2005; Ceballos et al., 2002). Por lo tanto hemos incluido un cuadro comparativo de las equivalencias a nivel de orden (Cuadro 1). Adicionalmente, tenemos las siguientes observaciones:

Orden Didelphiomorphia: seguimos a Hershkovitz (1992) que reconoció varias familias dentro de este órden y a Voss y Jansa (2003) en asignar al ratón tlacuache endémico al oeste de México al género Tlacuatzin (T. canescens).

Orden Primates: Con base en un conjunto grande de datos filogenéticos para las especies dentro del Orden Primates, Groves (2001) propuso la división de la familia Cebidae, con los géneros Alouatta y Ateles, los únicos que se distribuyen naturalmente en México, asignados dentro de la familia Atelidae. Asimismo, el nombre para la subfamilia de Alouatta, se cambió de Alouattinae a Mycetinae, derivado del sinónimo de Alouatta, Mycetes.

Orden Lagomorpha: Seguimos a Ruedas (1998) quien considera las poblaciones de Sylvilagus floridanus del sur de Texas y el norte de Coahuila como una especie diferente ( $S$. robustus).

Orden Erinaceomorpha: Aceptamos la validez de Scapanus anthony, especie endémica a la Sierra de Juárez, Baja California (Yates y Salazar, 2005). 
Cuadro 1. Cuadro de las equivalencias a nivel de orden, comparando a Wilson y Reeder, 1993 y 2005.

\begin{tabular}{ll}
\hline Órdenes Anteriores & Órdenes Actuales \\
\hline Didelphimorphia & Didelphimorphia \\
Xenarthra & Cingulata \\
& Pilosa \\
Insectivora & Erinaceomorpha \\
& Soricomorpha \\
Chiroptera & Chiroptera \\
Primates & Primates \\
Carnivora & Carnivora \\
Cetacea & Cetacea \\
Sirenia & Sirenia \\
Perissodactyla & Perissodactyla \\
Artiodactyla & Artiodactyla \\
Rodentia & Rodentia \\
Lagomorpha & Lagomorpha \\
\hline
\end{tabular}

Orden Soricomorpha: aceptamos las propuestas de Woodman y Timm (1999, 2000) para la reestructuración de varias especies dentro de Cryptotis y las de Carraway y Timm (2000) que reconocieron a tres especies de Notiosorex crawfordi, N. evotis y N. villai. Asimismo, incorporamos a N. cockrumi descrita recientemente para el suroeste de Estados Unidos de América y noroeste de México (Baker et al., 2003a).

Orden Chiroptera: Aceptamos que las poblaciones de México del género Centronycteris pertenecen a una especie (C. centralis) diferente a C. maximiliani (Simmons y Handley, 1998). El arreglo de las subfamilias dentro de Phyllostomidae todavía está bajo discusión. Wetterer et al. (2000) presentaron un análisis supuestamente robusto basado en "la evidencia total", proponiendo la existencia de siete subfamilias, pero Baker et al. (2000) analizaron un conjunto de caracteres diferentes (la secuencia del ADN del gene-2 de recombinación-activación) y sus datos contradicen algunas de las propuestas por Wetterer et al. (2000). Más recientemente, Baker et al. (2003b) analizaron la filogenia de 48 de los 53 géneros de la familia, basados en los datos de la secuencia del ADN mitocondrial de tres genes: $12 \mathrm{~S}$ rDNA, tRNA ${ }^{\text {val }}$ y 16S rRNA, utilizaron un análisis de congruencia digenómica en asociación de pruebas estadísticas robustas, realizando una propuesta filogenéticas muy sólida; dichos autores proponen la existencia de 11 subfamilias dentro de Phyllostomidae. Sin embargo, hay acuerdo en los tres estudios de que algunos 
grupos son monofiléticos, como Desmodontinae, Glossophaginae (para los géneros que se conocen en México) y Stenodermatinae (excepto Carollia). La monofilia de aquellos géneros tradicionalmente incluidos dentro de Phyllostominae permanece polémica, así como lo referente a la inclusión de Carollia dentro de Stenodermatinae. Aquí, nosotros seguimos la clasificación de McKenna y Bell (1997), reconociendo la subfamilia Phyllostominae sin designaciones de tribus y reteniendo Carollia dentro de la familia Stenodermatinae.

Seguimos a Simmons (2005) en reconocer a las poblaciones de Leptonycteris curasoae de México como una especie diferente (L. yerbabuenae). Asimismo, aceptamos su recomendación de que Artibeus intermedius es un sinónimo de A. lituratus. La situación de A. jamaicensis tryomylus es incierta, por lo que no lo incluimos en este listado, como sugiere Guerrero et al. (2004)

Consideramos que Micronycteris, previamente reconocido como monotípico, está realmente compuesto de varios géneros (Simmons y Voss, 1998; Wetterer et al., 2000). El nombre válido para las especies de Micronycteris con una muesca poco profunda en la banda de la oreja y que se distribuye en México y el norte de Centroamérica, es $M$. microtis en lugar de M. megalotis (Simmons, 1996). Aceptamos el registro de Trinycteris nicefori (Escobedo-Morales et al., en prensa). Reconocemos a Phylloderma como un género separado de Phyllostomus (Simmons y Voss, 1998; Wetterer et al., 2000). Aceptamos que Tonatia brasiliense y T. evotis pertenecen al genero Lophostoma (Lee et al., 2002).

Otra controversia que no ha sido resuelta, incluso con análisis detallados recientes (Baker et al., 2000, 2003b; Van Den Bussche et al., 1998; Wetterer et al., 2000), es si Dermanura es un subgénero de Artibeus o un género hermano del mismo. Nosotros pensamos que hasta que haya datos extensos que falsifiquen la relación de taxa hermanos, dichos taxa deberán reconocerse como géneros separados (sensu Owen, 1987). Incorporamos la propuesta de Baker et al. (2002) referente a la separación de las poblaciones de Carollia brevicauda en dos especies, correspondiendo al componente norteño que se distribuye en México la nueva designación de C. sowelli.

El uso de la subfamilia Myotinae y de la familia Antrozoidae sigue la propuesta de Simmons (1998). Sin embargo, debemos señalar que en el estudio sistemático más reciente de la Familia Vespertilionidae, con base en varios genes del ADN mitocondrial, Hoofer y Van Den Bussche (2003) proponen varios cambios, tanto a nivel genérico como supragenérico, incluyendo la incorporación de Antrozoidae sensu Simmons a la subfamilia Vespertilioninae. Aquí preferimos seguir la propuesta de Simmons (1998), puesto que coincide con la clasificación utilizada en Wilson y Reeder (2005).

Hemos incluido a una especie nueva de Natalus ( $N$. lanatus), descrita recientemente para México con base en caracteres morfológicos (Tejedor, 2005).

Myotis occultus es una especie válida, separada de $M$. lucifugus y que habita en el suroeste de EUA (Piaggio et al., 2002). Estos autores indicaron la necesidad de 
revisar las poblaciones que se distribuyen en México, pero sin proponer cambios al respecto. Aquí consideramos importante señalar dicho estudio, pero no realizar cambios hasta que las poblaciones mexicanas sean revisadas. Aceptamos que Cynomops mexicanus es el válido para la especie anteriormente designada como Molossops greenhalli mexicanus (Peters et al., 2002).

López-González y Presley (2001) estudiaron los murciélagos de tamaño mediano del género Molossus y reidentificaron al ejemplar procedente de Quintana Roo que correspondía al único registro en México de $M$. bondae. Dichos autores lo asignaron a $M$. aztecus, lo que les permite aseverar que Molossus bondae no se distribuye en el país. Wang et al. (2003) analizaron los patrones de distribución de los murciélagos de Michoacán, enlistando las especies Sturnira occidentalis y Myotis jalisciensis. Estos nombres no representan a alguna especie válida, por lo que no son considerados en este trabajo. Además, los mismos autores usan el nombre específico de Myotis leibii que ya había sido colocado bajo la sinonimia de M. ciliolabrum (ver Jones et al., 1988).

Orden Carnivora: Mercure et al. (1993) analizaron datos moleculares de las poblaciones de Vulpes que habitan en el sur de Estados Unidos, apoyando la anterior propuesta de que $V$. macrotis es una especie válida, separada de $V$. velox y que se distribuye hasta México. Aceptamos a Mustela nigripes en México, ya que fue reintroducida recientemente de manera exitosa en la región de Janos - Casas Grandes en el noroeste de Chihuahua (Pacheco et al., 2002). En el verano de 2002, se registró el primer hurón de patas negras nacido en tiempos históricos dentro de México (J. Pacheco, comunicación personal, 2003).

Seguimos a Dragoo y Honeycutt (1997) reconociendo la familia Mephitidae. Dragoo et al. (1993) analizaron datos alozímicos de secuencia de nucleótidos, proponiendo que las dos especies de Spilogale que se distribuyen en Estados Unidos y México, S. gracilis y S. putorius, son tan divergentes como las especies de Conepatus, por lo que reconocen la validez de ambas (Figura 1). Asimismo, estamos de acuerdo con la conclusión de Dragoo et al. (2003), que encontraron que Conepatus mesoleucus y C. leuconotus, representan a la misma especie y el nombre válido es el segundo.

Seguimos a Helgen y Wilson (2005) en considerar con base en un estudio morfométrico de los mapaches de México y Centroamérica que la especie de las Islas Marías es diferente a solo nivel subespecifico (Procyon lotor insularis). Recientemente se ha propuesto que el nombre genérico del jaguarundi sea Puma en lugar de Herpailurus (Wilson y Reeder, 2005). No seguimos esa propuesta hasta que este más sustentada.

Orden Artiodactyla: Al temazate de la península de Yucatán se le otorgó estado específico, quedando separado de M. americana con el binomio Mazama pandora (Medellín et al., 1998). Asimismo, seguimos a Geist (1998) que considera que 


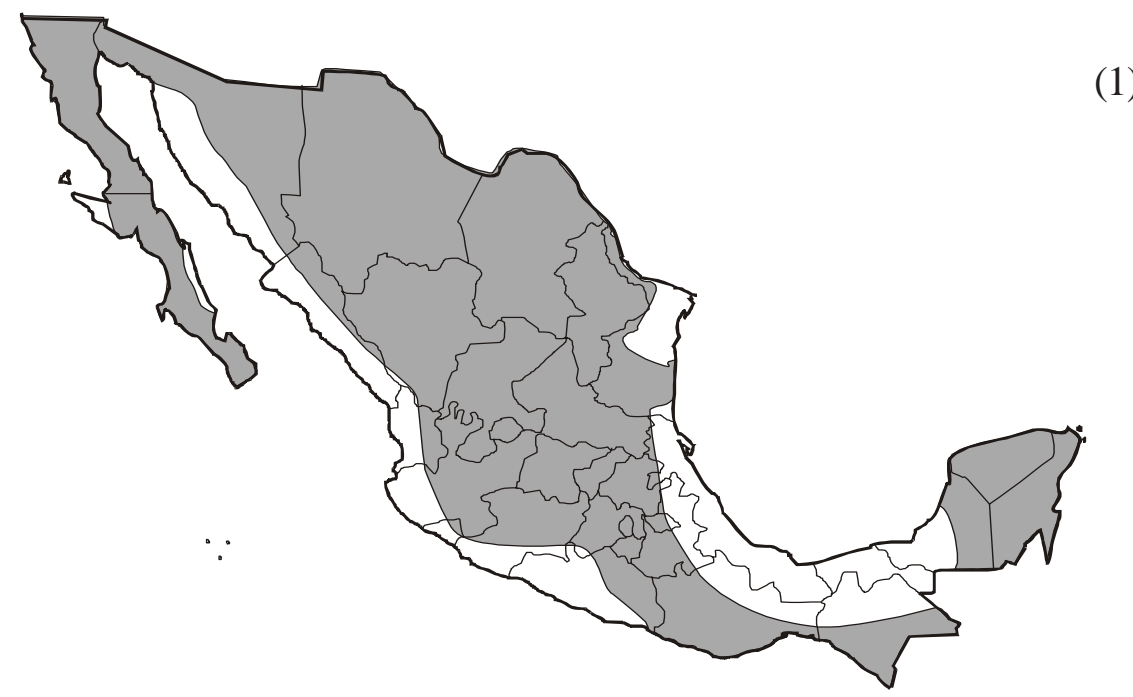

(1)

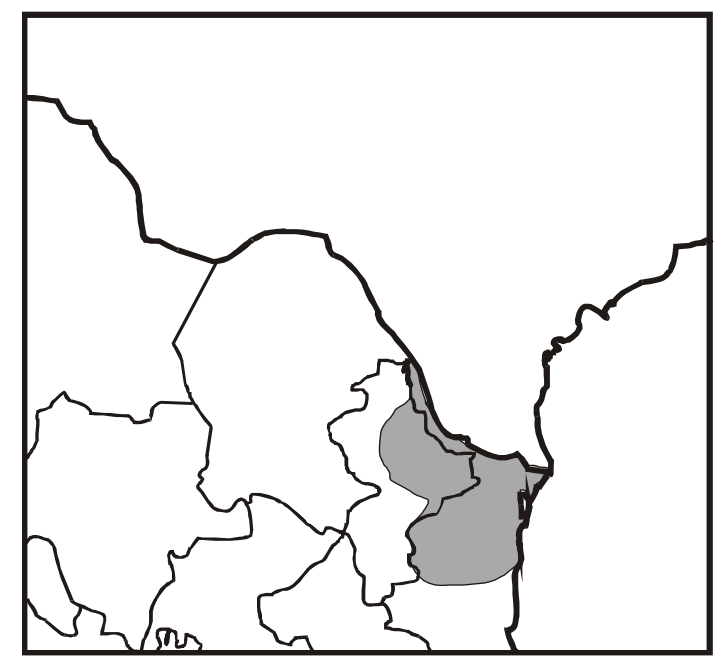

(2)

Figura 1. Distribución de Spilogale gracilis (1) y S. putorius (2) en México (modificada de Ceballos y Oliva, 2005). 
los temazates de México corresponden a Mazama temama en lugar de M. americana. No se siguió a Grubb (1993) ni Ramírez-Pulido et al. (1996) en el uso de Pecari tajacu para el pecarí de collar, reteniéndose el nombre de Tayassu tajacu con base de los argumentos proporcionados por Wright (1989). Seguimos el nombre de Bison en lugar de Bos.

Orden Cetacea: Los registros de Mesoplodon peruvianus de las proximidades de La Paz, Baja California Sur proceden de Urbán-R. y Aurioles-G. (1992). Una especie adicional no identificada de Mesoplodon fue grabada en película para México (Salinas y Ladrón de Guevara, 1993). Consideramos que dicha especie hasta ahora considerada como desconocida del Pacífico mexicano, corresponde a la recientemente descrita M. perrini de las costas de San Diego, California (Dalebout et al., 2002). La foca de Galápagos (Arctocephalus galapagoensis) fue recientemente registrada en la costa de Chiapas (E. Espinosa y G. Ceballos, observación personal, 2002).

Heyningy Perrin (1994) reconocieron a dos especies del delfín común, por lo que en México existe Delphinus capensis y D. delphis.

Orden Rodentia: Basándose en las relaciones evolutivas de ectoparásitos de los chichimocos, Jameson (1999) concluyó que los subgéneros Neotamias, Tamias y Eutamias deberían elevarse a tres géneros separados. Reciententemente, dicha conclusión fue apoyada por Piaggio y Spicer (2001) basados en el análisis de los datos de la secuencia del citocromo b. Aquí se sigue dicha propuesta, con Tamias striatus como la única especie que no queda dentro de los chichimocos americanos del género Neotamias; sin embargo, no se considera que la indicación de los mismos autores en referencia a agrupar diversas especies, entre ellas las que se distribuyen en México, en dos grupos ( $N$. quadrivittatus y $N$. merriami) sea una propuesta taxonómica formal.

Demastes et al. (2003), en su revisión filogenética de Pappogeomys alcorni utilizando el citocromo- $b$ mitocondrial de 424 pares de bases y con el apoyo del análisis morfométrico de 101 ejemplares de Pappogeomys, concluyen que P. alcorni es una subespecie disyunta de $P$. bulleri más que una especie monotípica. Hafner et al. (2004) estudiaron las relaciones filogenéticas de las cinco especies que conforman el grupo de Cratogeomys gymnurus, es decir C. fumosus, C. gymnurus, C. neglectus, C. tylorhinus y C. zinseri, a partir del ADN nuclear y mitocondrial, cromosomas y caracteres morfològicos. A pesar de que los caracteres morfológicos no permitieron discriminar los grupos, el estudio molecular mostró cinco clados que no corresponden con las especies actuales; cuatro de dichos grupos no se pueden definir claramente y quedaron agrupados en la especie politìpica C. fumosus. El quinto grupo se separa de los otros por un conjunto de caracteres que incluyen el genotipo nuclear, el número cromosómico diploide, la fauna parasitaria y los caracteres morfológicos cualitativos, pudiendo asignarla a la especie C. planiceps (Merriam, 1895) (Figura. 2). Ambas especies son endémicas del Eje Neovolcánico. 


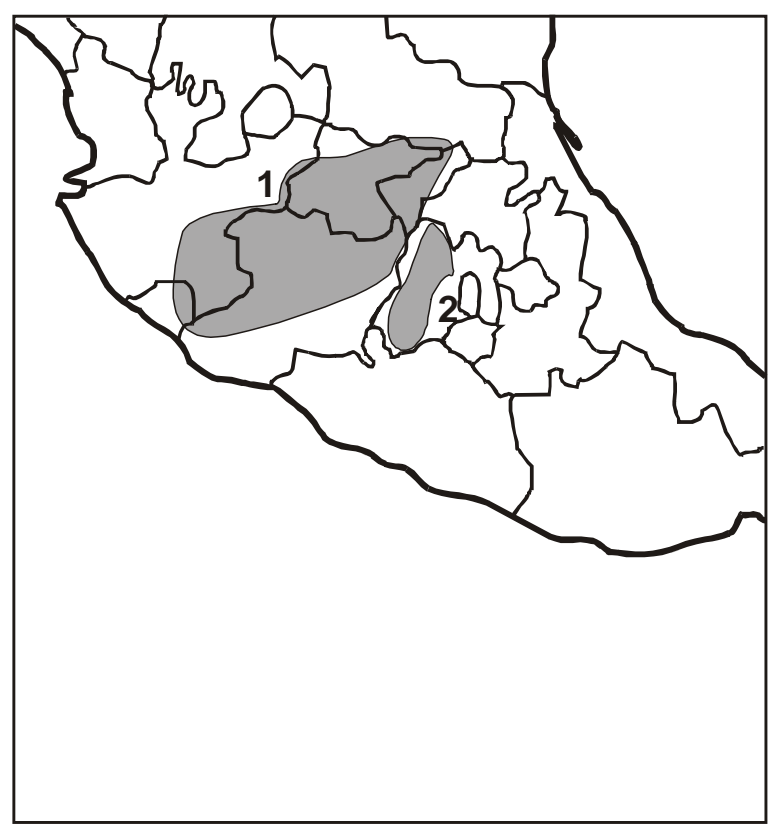

Figura 2. Distribución de Cratogeomys fumosus (1) y C. planiceps (2) en México (modificada de Hafner et al., 2004).

Hafner et al. (2005) han recomendado con base a un estudio de la variación cromosómica de Crateogeomys merriami, que existen tres especies bien diferenciadas genética y morfológicamente, denominadas C. merriami, C. fulvescens y C. perotensis, todas endémicas del Eje Neovolcánico (Figura 3).

Seguimos a Williams et al. (1993), quienes con base en estudios recientes de diversos investigadores, consideran a Heteromys goldmani como subespecie de $H$. desmarestianus, por lo que las especies reconocidas del género en México son $H$. desmarestianus, H.gaumeri y $H$ nelsoni. Consideramos a Chaetodipus anthonyi y C. dalquesti como especies válidas, distintas a C. fallax y C. arenarius (Hall, 1981), respectivamente, contrastando con la propuesta de Williams et al. (1993), quienes no justificaron la misma. Incluimos a Chaetodipus eremicus como diferente de C. penicillatus, siguiendo lo propuesto, con base en extensos análisis, por Lee et al. (1996). Las poblaciones de Chaetodipus baileyi al oeste del río Colorado, desde el sur de California a la Península de Baja California, recientemente se reconocieron como una especie distinta (C. rudinoris) con base al análisis de ADN mitocondrial por Riddle et al.(2000a). 


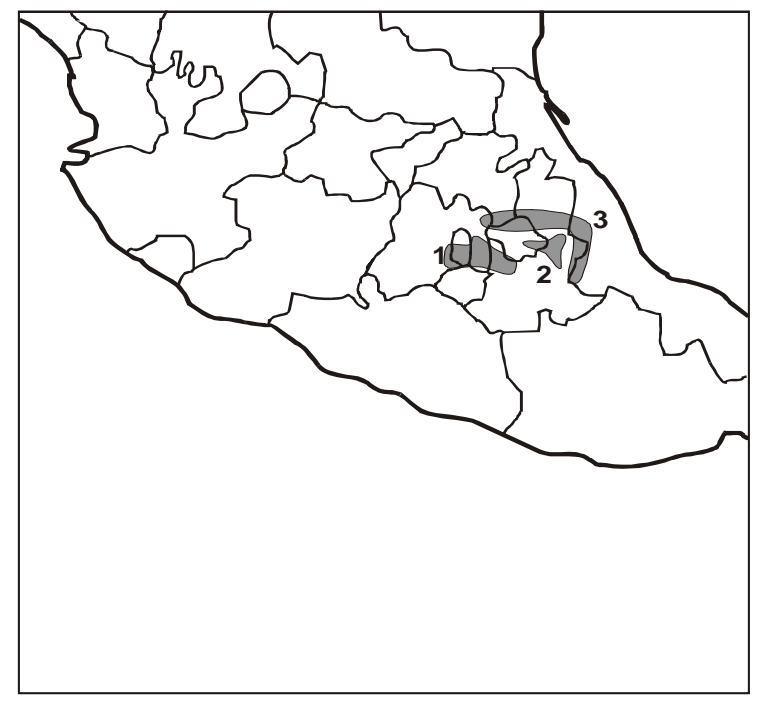

Figura 3. Distribución de Cratogeomys merriami(1), C. fulvescens(2) y C. perotensis en México (modificada de Hafner et al., 2005).

La especie Habromys schmidly fue descrita recientemente con base en ejemplares procedentes de Taxco, Guerrero, Zacualpan y Estado de Mexico (Romo et al., 2005). Esta especie es endémica del Eje Neovolcánico (Figura 4). Seguimos la recomendación de Carleton et al. (2002) en considerar a Habromys ixtlani como una especie diferente de $H$. lepturus. Esos mismos autores descubrieron a $H$. delicatulus de una localidad cercana a Jilotepec en el Estado de México. Ambas especies son endémicas de México (Figura 5).

De manera semejante, se reconocieron las poblaciones de Peromyscus eremicus al oeste del río Colorado, desde el sur de California a la Península de Baja California, como una especie distinta (Peromyscus fraterculus) por Riddle et al. (2000b). Peromyscus sagax es una especie válida, endémica al centro de Michoacán (Bradley et al., 1996). Bradley et al. (2004) describieron una nueva especie de Peromyscus, $P$. schmidlyi, con base en una poblacion de Durango, México que había sido considerada como parte de la variación cromosómica de $P$. boylii, pero que es más próxima a $P$. beatae y $P$. levipes (Figura 6).

Hafner et al. (2001) usaron datos genéticos y moleculares para evaluar el estado de especies insulares de Peromyscus frente a la costa de Baja California. Aquí no se sigue la propuesta que considera que $P$. stephani, $P$. interparietalis, $P$. caniceps y $P$. dickeyi son subespecies de $P$. boylii, $P$. eremicus, $P$. fraterculus y $P$. merriami, 


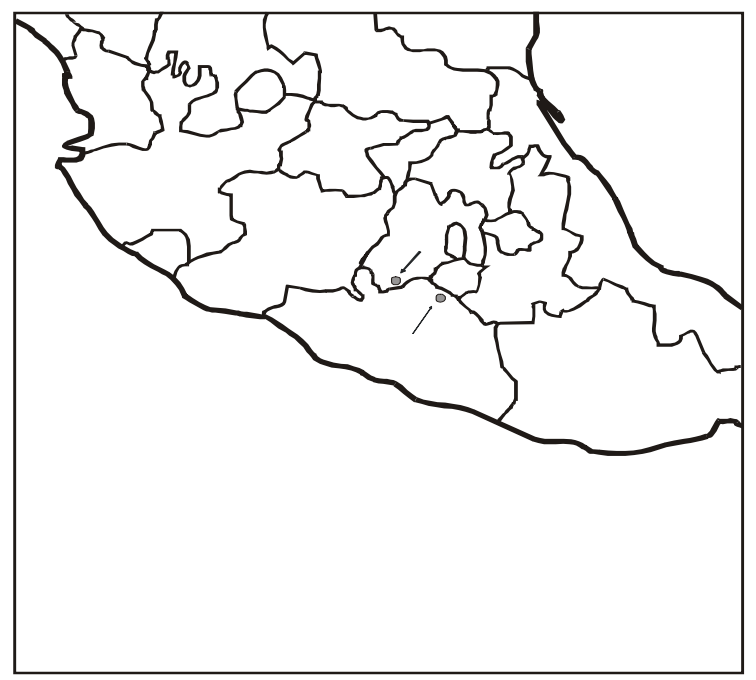

Figura 4. Distribución de Habromys schmidly en México (modificada de Romo et al., 2005).

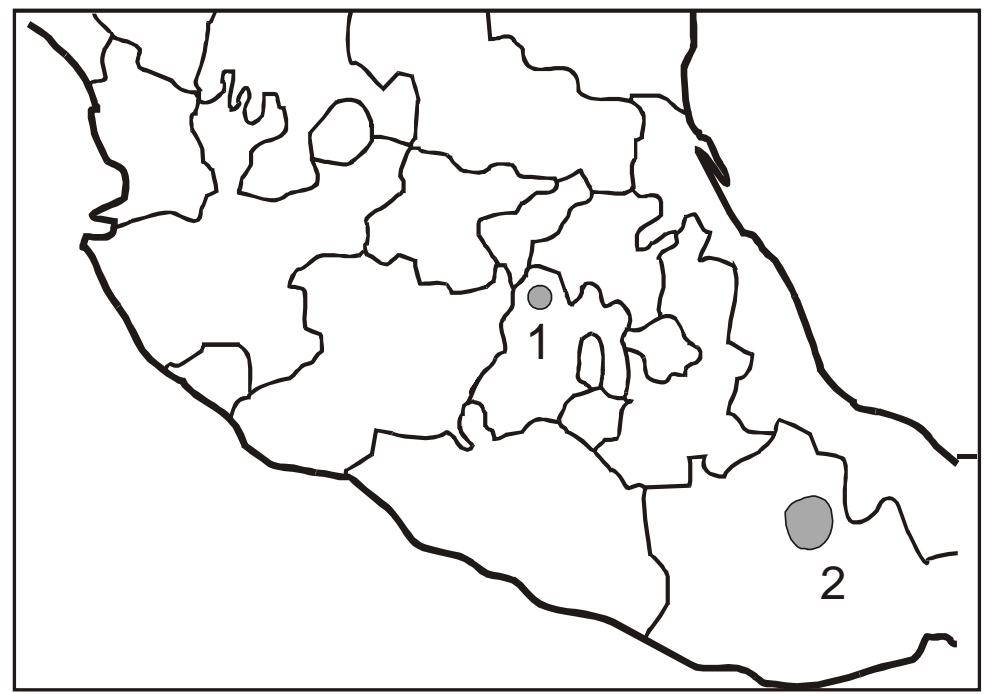

Figura 5. Distribución de Habromys delicatulus y H. ixtlani en México (modificada de Carleton et al., 2002). 


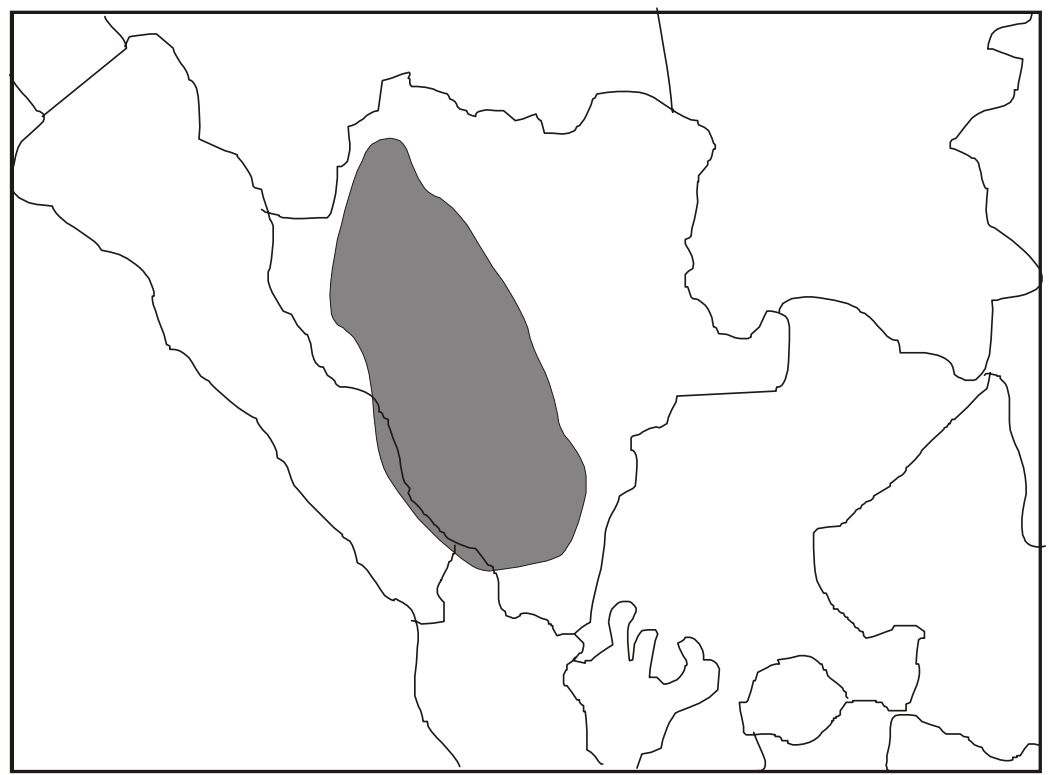

Figura 6. Distribución de Peromyscus schmidlyi en México (modificada de Hafner etal., 2005).

respectivamente. Deben usarse estudios morfométricos, cariotípicos y alozímicos adicionales para determinar el nivel taxonómico de diferencia de las poblaciones de las islas. De hecho, Carleton y Lawlor (2005) encontraron que P. stephani es una especie válida y que los ejemplares usados por Hafner et al. (2001) colectados por Sergio Ticul Álvarez, (D. Hafner, com. pers., 2005) para su estudio eran en realidad P. fraterculus.

Las poblaciones de Neotoma albigula que habitan al este del río Conchos (Chihuahua) son una especie diferente, Neotoma leucodon (Edwards et al., 2001). Asimismo, Edwards y Bradley (2002) analizaron las secuencias del gen del citocromo B del ADN mitocondrial de 15 individuos de seis poblaciones de Neotoma mexicana, y sus resultados les permiten sugerir que, al menos, dos de dichas poblaciones que se distribuyen en el sur ( $N$. m. isthmica) y sureste ( $N$. m. picta) de México, pueden representar especies hermanas de $N$. mexicana. R. Bradley (comunicación personal, 2003) nos confirmó que nuevos análisis fundamentan una propuesta formal.

La rata magueyera de patas grises, Neotoma fuscipes, está constituida por dos unidades taxonómicas aisladas, correspondiendo a las poblaciones del sur el nombre específico Neotoma macrotis, incluyendo las de México, sin subespecies reconocidas en este momento (Matocq, 2002). Reithrodontomys bakeri fue descrita recientemente con base en ejemplares de la Sierra de Guerrero (Bradley et al., 2004). 


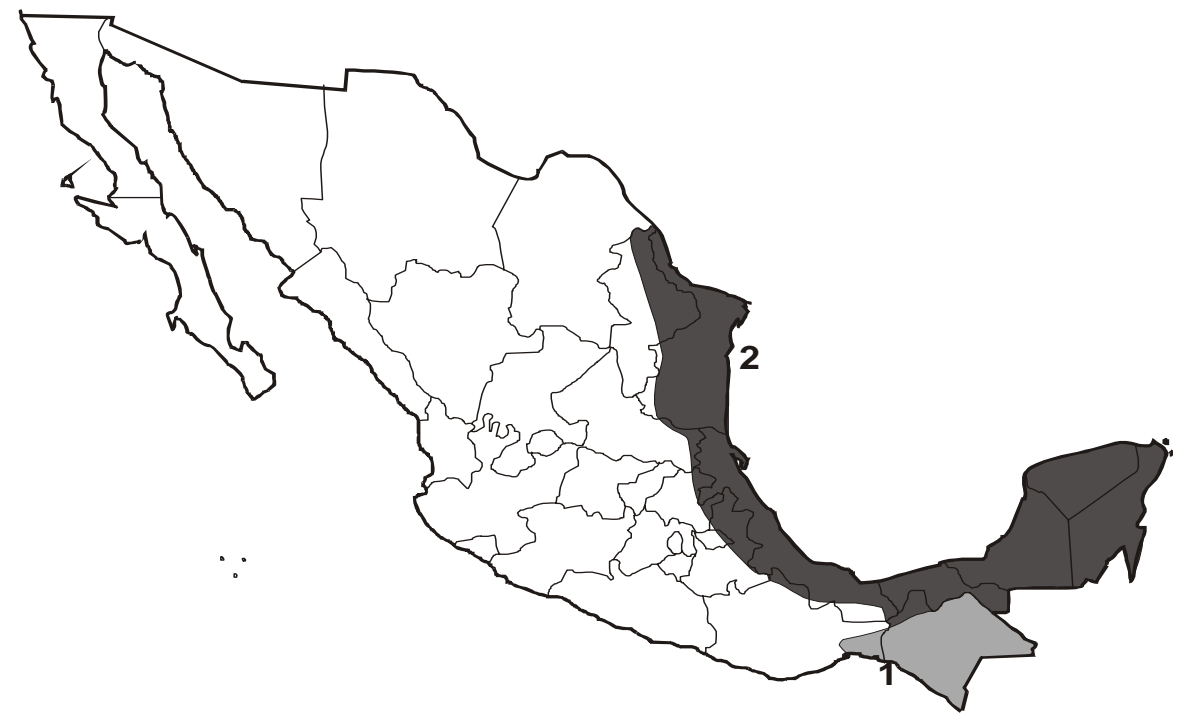

Figura 7. Distribución de Sigmodon hirsutus (1) y Sigmodon toltecus (2) en México (modificada de Carroll et al., 2005).

Peppers et al. (2002) estudiaron la variación de los nucleóticos en el gene mitocondrial citocromo- $b$ de la rata cañera Sigmodon, propusieron que $S$. toltecus, originalmente considerada una subespecies de $S$. hispidus, debe considerarse como una especie válida.

Carroll et al. (2005) proponen que varias subespecies anteriormente pertenecientes a Sigmodon hispidus, deben tener nivel específico, por lo que para México, se adicionan S. toltecus y $S$. hirsutus, esta última anteriormente conocida sólo para Sudamérica (Figura 7). Carroll y Bradley (2005) apoyan dicha propuesta y, con base en secuencias de nucleótidos, hallaron que S. alleni y $S$. hirsutus son especies hermanas y, a dicho grupo, se le añade $S$. toltecus. Por lo tanto, $S$. hispidus es una especie que no se encuentra ya en México.

Atendiendo la decisión de la Comisión Internacional para la Nomenclatura Zoológica (ICZN, 1998), se reconoce la familia Cuniculidae y el género Cuniculus como las categorías taxonómicas válidas para el taxón Cuniculus paca.

Para determinar la distribución y las afinidades zoogeográficas, recabamos información de diversas fuentes. Los patrones de distribución los determinamos usando los mapas de Ceballos y Oliva (2005). Clasificamos a los mamíferos mexicanos según su distribución geográfica reciente, como sigue: 1) las especies mexicanas compartidas con otros países norteamericanos (NA); 2) las especies mexicanas 
compartidas con otros países de Sudamérica (SA); 3) las especies con intervalos distributionales amplios que incluyen tanto Norte como Sudamérica (AM); 4) especies que son endémico a América Central, es decir México y Centroamérica (MA); y 5) las especies endémicas mexicanas (MX).

La lista de especies insulares la compilamos de Ceballos y Oliva (2005), Ceballos y Rodríguez (1993), Engstrom et al. (1989), Jones y Lawlor (1965), Lawlor (1983), Ramírez-Pulido y Müdespacher (1987), Sánchez-H. (1986) y Wilson (1991). Las especies se catalogaron como totalmente insulares, es decir que no está presente en el continente (I); continental (C); y continental-insular (IC), especies que combinan ambos patrones.

El estado de conservación lo compilamos de la lista mexicana de especies en riesgo de extinción (SEMARNAP, 2000), IUCN (Hilton-Taylor, 2004; también ver http:/ /www.redlist.org/search/search-expert.php) y CITES (2001; también ver http:// www.cites.org). CITES clasifica las especies sujetas al comercio internacional en tres apéndices: el Apéndice I que incluye "todas las especies amenazadas con extinción que están o pueden verse afectadas por el comercio. El comercio con los especímenes de estas especies debe estar sujeto a una regulación particularmente estricta para no poner en peligro su supervivencia posterior y sólo debe ser autorizado en las circunstancias excepcionales." El Apéndice II que incluye "todas las especies que, aunque no necesariamente ahora, pueden volverse amenazadas con la extinción al menos que el comercio en los especímenes de tales especies esté sujeto a una estricta regulación para evitar su utilización incompatible con su supervivencia, así como otras especies que deberán sujetarse a una regulación para que el comercio de especímenes de ciertas especies referidas en el párrafo anterior bajo un control eficaz." Finalmente, el Apéndice III incluye "especies que cualquier grupo identifica como que está(n) sujeta(s) a la regulación dentro de su jurisdicción con el propósito de prevenir o restringir la explotación, y que necesitan el cofuncionamiento de otros grupos en el control del comercio (también ver http://www.cites.org).

\section{Composición de Especies, Diversidad y Distribución}

La fauna de mamíferos de México incluye 529 especies nativas de 192 géneros, 47 familias y 12 órdenes (Cuadro 2). México es el tercer país en el mundo por lo que se refiere al número de especies de mamíferos, detrás de Indonesia y Brasil (Ceballos y Brown, 1995; Mittermeier et al., 1997). Los roedores y los murciélagos son los órdenes más ricos en especies, que contribuyen arriba del 77\% de todas las especies (Cuadro 2). Otros órdenes que contribuyen con números grandes de especies son los carnívoros, cetáceos, insectívoros y lagomorfos. En promedio, cada género está representado por al menos dos especies; sin embargo, hay géneros particularmente ricos en especies como Peromyscus (50 spp), Myotis (19 spp), Neotoma (19 spp), 
vol. 9

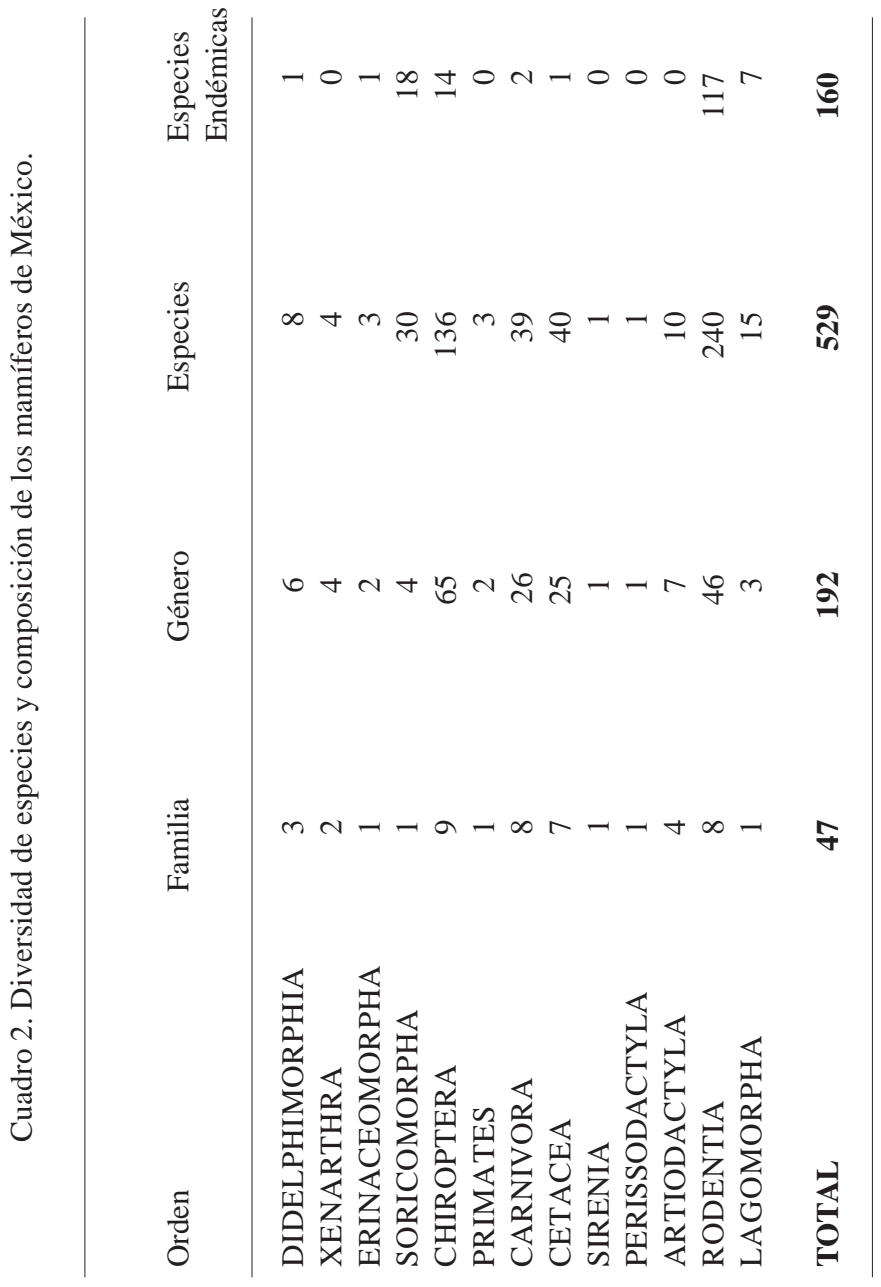


Chaetodipus (18 spp), Reithrodontomys (14 spp), y Cryptotis (13 spp).

Treinta por ciento (160 spp) de todas las especies y cuatro por ciento de géneros (Tlacuatzin, Megasorex, Musonycteris, Pappogeomys, Zygogeomys, Osgoodomys, Megadontomys, Nelsonia, Neotomodon, Xenomys, Hodomys, Romerolagus) son endémicos al país (también ver Ceballos y Rodríguez, 1993; Ceballos et al., 1998; Ramírez-Pulido y Müdespacher, 1987). Las especies endémicas pertenecen a 7 órdenes y 12 familias y la mayoría (115 spp; 71\%) son roedores.

La fauna restante es una combinación de elementos neotropicales, neárticos o especies compartidas que constituyen dos tercios de las especies mexicanas (también ver Alvarez y de La Chica, 1974; Arita, 1993; Ortega y Arita, 1998). Se han encontrado patrones similares en muchos otros grupos de plantas y animales (Ramammorthy et al., 1993). Ningún otro país continental en el mundo, sin embargo, contiene los límites completos entre dos regiones biogeográficas.

La proporción de especies de mamíferos terrestres entre los órdenes también muestra que la fauna mexicana es el resultado de la combinación de elementos neárticos y de neotropicales. En todos los órdenes excepto uno, la proporción de especies para México es intermedia entre las que provienen de la región neártica y los reinos de Neotropical. La excepción es el orden Chiroptera que incluye más de 30\% de la fauna mexicana de mamíferos terrestres y está principalmente compuesto por especies de afinidad Neotropical.

\section{Estado de conservación}

Los mamíferos de México están enfrentando problemas ambientales severos que afectan su supervivencia a largo plazo. Por lo menos ocho especies y, 229 (44\%) están clasificadas que enfrentan problemas de conservación (Ceballos, 1993; Ceballos y Oliva, 2005). Los números y proporciones de taxa extintos y que están en peligro indican que México también está entre los países con mayores problemas en el mundo en estas categorías (Ceballos y Brown, 1995; Hilton-Taylor, 2004).

Las especies extintas documentadas incluyen cuatro especies insulares de roedores y un pinnípedo. Todos los roedores, incluso Peromyscus pembertoni de la isla de San Pedro Nolasco, Neotoma anthonyi de la isla de Todos Santos, Neotoma bunkeri de las islas de Coronado, y Oryzomys nelsoni y Peromyscus madrensis de las islas de Tres Marías, desaparecieron como consecuencia de la introducción de ratas domésticas (Rattus spp), ratones (Mus musculus) y gatos (Felis catus) (Ceballos y Navarro, 1991; Lawlor, 1983; Mellink, 1992; Smith et al., 1993; Wilson, 1991). Se tienen datos que sugieren que dos especies adicionales pueden estar extintas: Peromyscus guardia de las islas Ángel de la Guarda, Mejía, Granito y Estanque (Mellink et al., 2002) y Dipodomys gravipes del Valle de San Quintin en Baja California (Ceballos y Rodríguez, 1993; E. Mellink, com. pers., 2001). La foca monje del Caribe (Monachus 
tropicalis) que habitaba en las aguas de Cuba, Jamaica y la Península de Yucatán, se extinguió alrededor de 1952 (Cole et al., 1994; Villa-R. et al., 1986). Adicionalmente, Myotis planiceps y M. milleri están consideradas extintas por la IUCN (Hilton-Taylor, 2004). Sin embargo, M. milleri está considerada como una subespecie de M. evotis (Manning, 1993) y M. planiceps fue recientemente reencontrada (Arroyo-Cabrales et al., 2005).

Aunque seis especies fueron consideradas como extirpadas de México por Ceballos y Navarro (1991), recientemente se encontró una de ellas, otra fue reintroducida con éxito y una más recolonizó espontáneamente en México. Hasta hace poco, el bisonte (Bison bison) se creía extirpado México (Anderson, 1972; Ceballos y Navarro, 1991; Leopold, 1965); sin embargo, una población salvaje remanente a lo largo de la frontera de Chihuahua con Nuevo México, se descubrió a principios de los 1990 (Pacheco et al., 2002). En cualquier caso, la especie debe ser considerada como críticamente en peligro. El wapití (Cervus elaphus) probablemente se extirpó a principios del último siglo (Leopold, 1959) pero ha sido reintroducido con éxito en Coahuila (Robles Gil et al., 1993). La nutria marina (Enhydra lutris) desapareció a principios de este siglo de las aguas mexicanas (Ceballos y Navarro, 1991); sorprendentemente, algunos individuos se han encontrado cerca de la Isla de Cedros y de la Bahía Magdalena, en la costa de la Península de Baja California (Gallo, 1997; Rodríguez-Jaramillo y Gendron, 1996). En 1950 la nutria de río norteña (Lontra canadensis) había desaparecido de los ríos Colorado y Bravo (Ceballos y Navarro, 1991); sin embargo, hay una grabación reciente de una nutria de agua dulce en Tamaulipas (G. Ceballos, obs. pers.) que representa a esta especie. El último oso pardo mexicano (Ursus arctos horribilis) se cazó en los 1960s en la Sierra Nido, Chihuahua (Brown, 1985). El lobo mexicano (Canis lupus baileyi) está extinto en libertad, pero unos pocos sobreviven en cautiverio (Ceballos y Navarro, 1991).

Los mamíferos mexicanos están sub-representados en las listas internacionales de especies con problemas de conservación (Figura 3). Doscientas veintinueve especies están consideradas por la nueva legislación mexicana como en peligro, amenazadas o bajo protección especial (SEMARNAP, 2002), mientras que sólo 58 mamíferos mexicanos están incluidos en CITES y 83 en las listas de IUCN. Las diferencias más obvias están en los casos que consideran a mamíferos pequeños. Por ejemplo, 38 murciélagos y 17 insectívoro son considerados por SEMARNAT, mientras que ninguno está incluido en CITES y sólo 19 (15 murciélagos y 4 insectívoros) en IUCN. De manera similar, CITES considera cuatro roedores mexicanos, IUCN incluye 35 y SEMARNAT enlista 88 especies de preocupación. Recíprocamente, la mayoría de los cetáceos mexicanos está incluido en CITES, mientras que este grupo está subrepresentado en la lista de IUCN. El sesgo en los listados de CITES indudablemente se relaciona con objetivo de esa convención, proteger sólo aquellas especies que se sujetan al comercio internacional, que son principalmente las especies grandes. Las 
regulaciones internacionales protegen algunas especies de mamíferos mexicanos, pero estas regulaciones son claramente inadecuadas si la protección de la diversidad del país es la meta de la conservación.

\section{Especies introducidas}

En México hay poblaciones establecidas de mamíferos domésticos, incluyendo perros, gatos, asnos, cerdos, cabras, ovejas y conejos. Adicionalmente hay poblaciones silvestres de por lo menos tres especies introducidas, incluso el borrego berberisco (Ammotragus lervia), el jabalí europeo (Sus scrofa) y el coipu sudamericano (Myocastor coypus; Arita y Ceballos, 1997), aunque hay sesenta especies de mamíferos introducidos bajo diferentes regímenes de manejo y libertad que están siendo analizados (R. Medellín comp pers., 2006). El berberisco fue introducido hace tres décadas y presentemente se distribuye en los estados de Nuevo León, Coahuila y San Luis Potosí; su intervalo geográfico de distribución todavía está aumentando (Gray y Simpson, 1980; E. Mellink, com. pers., 2000). Las poblaciones establecidas de jabalí europeo son conocidas en la Sierra Nido, Chihuahua (G. Ceballos, obs. pers.), la Reserva de la Biosfera Mapimí, Durango (Weber, 1995) y el noroeste de Durango del noroeste (R. Muñíz M., pers. com., 2000). El coipu es nativo de América del Sur; se introdujeron poblaciones accidentalmente en Louisiana, E. U. y se dispersó a Texas. Esa especie ha colonizado recientemente el río Bravo desde el delta aguas arriba al Parque Nacional Big Bend (Texas) - Maderas del Carmen (Coahuila) y la Laguna Madre en Tamaulipas (J. Carrera, R. Soto, com. pers., 1997).

\section{CONCLUSIÓN}

México tiene 528 especies de mamíferos que justifican plenamente la inclusión del país dentro del grupo de países megadiversos (aquellos que poseen más del 10\% las especies biológicas del mundo en su territorio). Aunque el conocimiento de los mamíferos en México tiene una tradición larga y ha aumentado rápidamente en los años recientes, se requieren más estudios para entender la biología de dichas especies y su estado de conservación. En conjunto, debido al grado de conocimiento de mamíferos, se espera que al menos 247 nuevas especies de mamíferos se describirán en el Mundo hasta el año 2032 (Medellín y Soberón, 1999). Otros investigadores han demostrado que todavía estamos lejos de lograr una estimación realista de los números de especies vivientes de mamíferos (Patterson, 2001). Este problema, junto con el conocimiento relativamente limitado y parcial de las faunas locales en México (Bojórquez-Tapia et al., 1994), es una virtual garantía de que el número de especies de mamíferos registrados para México (y el mundo entero) continuará aumentando en los 
próximos años. El advenimiento de técnicas especializadas en los estudios de genética molecular ha permitido un acercamiento mucho más integrado y realista para entender las afinidades filogenéticas y las relaciones evolutivas de los diferentes grupos. Estas técnicas han permitido la determinación de especies hermanas que serían indistinguibles por los métodos convencionales. Al continuar las nuevas técnicas evolucionando y refinándose, seguro que el número de especies también aumente.

El número de especies nativas de mamíferos mexicanos es 528 a partir de esta publicación. Otros países con números similares incluyen Indonesia, Brasil, y China. Estos datos colocan a México dentro de los tres países más ricos en especies de mamíferos.

Es probable que estos números cambien en el futuro cercano debido a las razones descritas arriba, aunque está claro que México permanecerá como un país megadiverso que contiene por lo menos $12 \%$ de las especies de mamíferos en aproximadamente $1.6 \%$ de la superficie de la tierra emergida del mundo.

\section{LITERATURACITADA}

Álvarez, T. y F. de Lachica. 1974. Zoogeografía de los vertebrados de México. Pp. 219-302, en: El escenario geográfico. Recursos naturales. Secretaría de Educación Pública e Instituto Nacional de Antropología e Historia, México.

Anderson, S. 1972. Mammals of Chihuahua. Taxonomy and Distribution. Bulletin of the American Museum of Natural History, 148:149-410.

Arita, H. T. 1993. Riqueza de especies de la mastofauna de México. Pp. 109-125, en: Avances en el estudio de los mamíferos de México (R. A. Medellín y G. Ceballos, eds.). Asociación Mexicana de Mastozoología, A. C., México D.F..

Arita, H. T. y G. Ceballos. 1997. Los mamíferos de México: distribución y conservación. The mammals of México: distribution and conservation. Revista Mexicana de Mastozoología, 2:33-71.

Arroyo-Cabrales, J., E. K. V. Kalko, R. K. LaVal, J. E. Maldonado, R. A. Medellín, O. J. Polaco y B. Rodríguez-Herrera. 2005. Rediscovery of the Mexican flat-headed bat Myotis planiceps (Vespertilionidae). Acta Chiropterologica, 7:309-314.

Aurioles, G. D. 1993. Biodiversidad y estado actual de los mamíferos marinos de México. Revista Mexicana de Historia Natural, Volumen especial, 44:397-412.

Baker, R. J., S. R. Hoofer, C. A. Porter y R. A. Van Den Bussche. 2003b. Diversification among New World leaf-nosed bats: an evolutionary hypothesis and classification inferred from digenomic congruence of DNA sequence. Occasional Papers The Museum, Texas Tech University, 230:1-29.

Baker, R. J., M. B. O’Neill y L. R. McAliley. 2003a. A new species of desert shrew, Notiosorex, based on nuclear and mitochondrial sequence data. Occasional Papers The Museum, Texas Tech University, 222:1-12.

Baker, R. J., C. A. Porter, J. C. Patton y R. A. Van Den Bussche. 2000. Systematics of bats of the family Phyllostomidae based on RAG2 DNA sequences. Occasional Papers The Museum, Texas Tech University, 202:i + 1-16. 
Baker, R. J., S. Solari y F. G. Hoffmann. 2002. A new Central American species from the Carollia brevicauda complex. Occasional Papers The Museum, Texas Tech University, 217:i + 1-11.

Bojórquez-Tapia, L. A., P. Balvanera y A. D.Cuarón.1994. Biological inventories and computer data bases: their role in environmental assessments. Environmental Management, 18:775-785.

Bradley, R. D., D. J. Schmidly y C. W. Kirpatrick. 1996. The relationships of Peromyscus sagax to the $P$. boylii and $P$. truei species groups in Mexico based on morphometric, karyotipic, and allozymic data. Pp. 95-106, en: Contributions in Mammalogy: A memorial volume honoring Dr. J. K. Jones, Jr. (H. H. Genoways y R. J. Baker, eds.). Museum of Texas Tech University, Lubbock, Texas.

Bradley, R. D., D. S. Carroll, M. L. Haynie, R. Muñiz Martinez, M. J. Hamilton y C. W. Kilpatrick. 2004. A new species of Peromyscus from western Mexico. Journal of Mammalogy, 85:1184-1193.

Bradley, R. D., F. Mendez-Harclerode, M. J: Hamilton y G. Ceballos. 2004. A new species of Reithrodontomys from Guerrero, Mexico. Occasional Papers, Museum of Texas Tech University, 231:i + 1-12.

Brown, D. E. 1985. The grizzly in the Southwest. University of Oklahoma Press, Norman.

Carleton, M. D., O. Sánchez y G. Urbano Vidales. 2002. A new species of Habromys (Muroidea: Neotominae) from México, with generic review of species definitions and remarks on diversity patterns among Mesoamerican small mammals restricted to humid montane forests. Proceedings of the Biological Society of Washington, 115:488-533.

Carleton, M. D. y T. E. Lawlor. 2005. Peromyscus from Santa Catalina Island, Sea of Cortez, Mexico: taxonomic identities and biogeographic implications. Journal of Mammalogy, 86:814-825.

Carraway, L. N. y R. M. Timm. 2000. Revision of the extant taxa of the genus Notiosorex (Mammalia: Insectivora: Soricidae). Proceedings of the Biological Society of Washington, 113:302-318.

Carroll, D. S. y R. D. Bradley. 2005. Systematics of the genus Sigmodon: DNA sequences from beta-fibrinogen and cytochrome b. The Southwestern Naturalist, 50:342-349.

Carroll, D. S., L. L. Peppers y R. D. Bradley. 2005. Molecular systematics and phylogeography of the Sigmodon hispidus species group. Pp. 87-99, en: Contribuciones Mastozoológicas en Homenaje a Bernardo Villa (V. Sánchez-Cordero y R. A. Medellín, eds.). Instituto de Biología e Instituto de Ecología, UNAM y Comisión Nacional para el Conocimiento y Uso de la Biodiversidad, México, D.F.

Ceballos, G. 1993. Especies en peligro de extinción. Revista Ciencias, Número especial 7:5-10.

Ceballos, G. y J. H. Brown. 1995. Global patterns of mammalian diversity, endemicity, and endangerment. Conservation Biology, 9:559-568.

Ceballos G. y D. Navarro. 1991. Diversity and conservation of Mexican mammals. Pp. 167198, en: Topics in Latin American mammalogy: history, biodiversity, and education (M. A. Mares and D. J. Schmidly, eds.). University of Oklahoma Press, Norman.

Ceballos, G. y G. Oliva (coords.) . 2005. Los Mamíferos Silvestres de México. Fondo de Cultura Económica y CONABIO. Hong Kong. 
Ceballos, G. y P. Rodríguez. 1993. Diversidad y conservación de los mamíferos de México: II. Patrones de endemicidad. Pp. 87-108, en: Avances en el estudio de los mamíferos de México (R. A. Medellín y G. Ceballos, eds.). Asociación Mexicana de Mastozoología, A. C., México D.F.

Ceballos, G., P. Rodríguez y R. A. Medellín. 1998. Assessing conservation priorities in megadiverse Mexico: mammalian diversity, endemicity, and endangerment. Ecological Applications, 8:8-17.

Ceballos, G., J. Arroyo-Cabrales y R. A. Medellín. 2002. The mammals of Mexico: composition, distribution and conservation status. Occasional Papers, Texas Tech University, 218:1-27.

Cervantes, F. A., A. Castro-C. y J. Ramírez-P. 1994. Mamíferos terrestres nativos de México. Anales del Instituto de Biología, Universidad Nacional Autónoma de México, Serie Zoología, 65:177-190.

CITES. 2001. Annotated CITES Appendices and Reservations. UNEP-World Conservation Monitoring Centre, Geneve, Switzerland.

Cole, F. R., D. M. Reeder y D. E. Wilson. 1994. A synopsis of distribution patterns and the conservation of mammal species. Journal of Mammalogy, 75:266-276.

Dalebout, M. L., J. G. Mead, C. S. Baker, A. L. Van Helden y A. N. Baker. 2002. A new species of beaked whale Mesoplodon perrini sp. n. (Cetacea: Ziphiidae) discovered through phylogenetic analyses of mitochondrial DNA sequences. Marine Mammal Science, 18:577608.

Demastes, J. W., A. L. Butt, M. S. Hafner y J. E. Light. 2003. Systematics of a rare species of pocket gopher, Pappogeomys alcorni. Journal of Mammalogy, 84:753-761.

Dragoo, J. W., R. D. Bradley, R. L. Honeycutt y J. W. Templeton. 1993. Phylogenetic relationships among the skunks: a molecular perspective. Journal of Mammalian Evolution, 1:255-267.

Dragoo, J. W. y R. L. Honeycutt. 1997. Systematics of mustelid-like carnivores. Journal of Mammalogy, 78:426-443.

Dragoo, J. W., R. L. Honeycutt y D. J. Schmidly. 2003. Taxonomic status of white-backed hog-nosed skunks, genus Conepatus (Carnivora: Mephitidae). Journal of Mammalogy, 84:159-176.

Edwards, C. W. y R. D. Bradley. 2002. Molecular systematics and historical phylobiogeography of the Neotoma mexicana group. Journal of Mammalogy, 83:20-30.

Edwards, C. W., C. F. Fulhorst y R. D. Bradley. 2001. Molecular phylogenetics of the Neotoma albigula species group: further evidence of a paraphyletic assemblage. Journal of Mammalogy 82:267-279.

Engstrom, M. D., C. A. Schmidt, J. C. Morales y R. C. Dowler. 1989. Records of mammals from Isla Cozumel, Quintana Roo, Mexico. The Southwestern Naturalist, 34:413-415.

Escobedo-Morales, L. A., L. León-Paniagua, J. Arroyo-Cabrales y F. Greenaway. En prensa. New distributional records for mammals from the State of Chiapas, México. The Southwestern Naturalist, 51(2).

Gallo R., J. P. 1997. Situación y distribución de las nutrias en México, con énfasis en Lontra longicaudis annectens Major, 1897. Revista Mexicana de Mastozoología, 2:10-32. 
Geist, V. 1998. Deer of the wordl. Ther evolution, behavior and ecology. Stackpole Books, Mechanicsburg, Pensylvania.

Guerrero, J. E. De Luna y D. González. 2004. Taxonomic status of Artibeus jamaicensis triamylus inferred from molecular and morphometric data. Journal of Mammalogy, 85: 866-874.

Gray, G. G. y C. D. Simpson. 1980. Ammotragus lervia. Mammalian Species, 144:1-7.

Groves, C. 2001. Primate Taxonomy. Smithsonian Institution Press, Washington, D.C.

Hafner, D. J., B.R. Riddl, y S. T. Alvarez-Castañeda. 2001. Evolutionary relationships of white-footed mice (Peromyscus) on islands in the Sea of Cortez, Mexico. Journal of Mammalogy, 82:775-790.

Hafner, M. S., T. A. Spradling, J. E. Light, D. S. Hafner y J. R. Demboski. 2004. Systematic revision of pocket gophers of the Cratogeomys gymnurus species group. Journal of Mammalogy, 85:1170-1183.

Hafner, M. S., J. E. Light, D. J. Hafner, S. V. Brant, T. A. Spradling y J. W. Demastes. 2005. Cryctic species in the mexican pocket gopher Cratogeomys merriami. Journal of Mammalogy, 86(6):1095-1108.

Hall, E. R. 1981. The mammals of North America. Segunda Edicion. John Wiley and Sons, New York.

Helgen, K. M. y D. E. Wilson. 2005. A systematic and zoogegraphic of the raccons of Mexico and Central America. Pp. 221-236. en: Contribuciones mastozoológicas en homenaje a Bernardo Villa (V. Sánchez-Cordero y R. A. Medellín, eds.). Instituto de Biología, UNAM; CONABIO. México, D.F.

Heyning, J. E. y W. F. Perrin. 1994. Evidence for two species of common dolphins (Genus Delphinus) from the eastern north Pacific. Contributions in Science, 442:35.

Hershkovitz, P. 1992. The South America genus Gracilinanus Gardner and Creighton, 1989 (Marmosidae, Marsupialia): a taxonomic review with notes on general morphology and relationships. Fieldiana Zoology (new series), 70:1-56.

Hilton-Taylor, C. 2004. 2004 IUCN red list of threatened specie. IUCN, Glanz, Suiza.

Hoofer, S. R. y R. A. Van Den Bussche. 2003. Molecular phylogenetics of the chiropteran family Vespertilionidae. Acta Chiropterologica, 5(supplement):1-63.

ICZN.1998. Opinion 1894. Regnum Animale..., Ed. 2 (M.J. Brisson, 1762): rejected for nomenclatural purposes, with the conservation of the mammalian generic names for Philander (Marsupialia), Pteropus (Chiroptera), Glis, Cuniculus and Hydrochoerus (Rodentia), Meles, Lutra and Hyaena (Carnivora), Tapirus (Perissodactyla), Tragulus and Giraffa (Artiodactyla). Bulletin Zoological Nomenclature, 55:64 - 71.

Jameson, E. W., Jr. 1999. Host-ectoparasite relationships among North American chipmunks. Acta Theriologica, 44:225-231.

Jones, C., R. S. Hoffmann, D. W. Rice, M. D. Engstrom, R. D. Bradley, D. S. Schmidly, C. A. Jones y R. J. Baker. 1997. Revised checklist of North American mammals north of Mexico, 1997. Occasional Papers, Museum of Texas Tech University, 173:1-19.

Jones, J. K., Jr., J. Arroyo-Cabrales y R. D. Owen. 1988. Revised checklist of bats (Chiroptera) of Mexico and Central America. Occasional Papers, Museum of Texas Tech University, 120:1-34. 
Jones, J. K., Jr. y T. E. Lawlor. 1965. Mammals from Isla Cozumel, Mexico, with description of a new species of harvest mouse. University of Kansas Publications, Museum of Natural History, 16:409-419.

Lawlor, T. E. 1983. The mammals. Pp. 265-289, en: Island Biogeography in the Sea of Cortez (T. J. Case y M. L. Cody, eds.). University of California Press, Berkeley.

Lee, T. E., Jr., B. Riddle y P. L. Lee. 1996. Speciation in the desert pocket mouse (Chaetodipus penicillatus Woodhouse). Journal of Mammalogy, 77:58-68.

Lee, T. E., Jr., S. R. Hoofer y R. A. Van Den Bussche. 2002. Molecular phylogenetics and taxonomic revision of the genus Tonatia (Chiroptera: Phyllostomidae). Journal of Mammalogy, 83: 49-57.

Leopold, A. S. 1959. Wildlife of Mexico. University of California Press, Berkeley.

Leopold, A. S. 1965. Fauna silvestre de México: aves y mamíferos de caza. Instituto Mexicano de Recursos Naturales Renovables, México D. F.

López-González, C. y S. J. Presley. 2001. Taxonomic status of Molossus bondae J. A. Allen, 1904 (Chiroptera: Molossidae), with description of a new subspecies. Journal of Mammalogy, 82:760-774.

Manning, R. W. 1993. Systematics and evolutionary relationships of the long-eared myotis, Myotis evotis (Chiroptera; Vespertilionidae). Special Publications, Museum of Texas Tech University, 37:1-58.

Matocq, M. D. 2002. Morphological and molecular analysis of a contact zone in the Neotoma fuscipes species complex. Journal of Mammalogy, 83:866-883.

McKenna, M. C. y S. K. Bell. 1997. Classification of mammals above the species level. Columbia University Press, New York.

Medellín, R. A. y J. Soberón. 1999. Predictions of mammal diversity on four land masses. Conservation Biology, 13:143-149.

Medellín, R. A., A.L. Gardner y J. M. Aranda. 1998. The taxonomic status of the Yucatán brown brocket, Mazama pandora (Mammalia: Cervidae). Proceedings of the Biological Society of Washington, 111:1-14.

Mellink, E. 1992. The status of Neotoma anthonyi (Rodentia, Muridae, Cricetidae) of Todos Santos Island, Baja California, Mexico. Bulletin of the Southern California Academy of Sciences, 91:137-140.

Mellink, E., G. Ceballos y J. Luévano. 2002. Population demise and extinction threat of the Angel de la Guarda deer mouse (Peromyscus guardia). Biological Conservation, 108:107111.

Mercure, A., K. Ralls, K. P. Koepfli y R. K. Wayne. 1993. Genetic subdivisions among small canids: mitochondrial DNA differentiation of swift, kit, and arctic foxes. Evolution, 47:1313-1328.

Mittermeier, R. A. y C. Goettsch de M. 1992. La importancia de la diversidad biológica de México. Pp. 63-73, en: México ante los retos de la biodiversidad (J. Sarukhán y R. Dirzo, eds.). Comisión Nacional para el Conocimiento y Uso de la Biodiversidad, México, D. F.

Mittermeier, R. A., P. Robles G. y C. Goettsch de M. 1997. Megadiversidad. Los países biológicamente más ricos del mundo. Agrupación Sierra Madre, S. C. y CEMEX, México, D. F. 
Ortega, J. y H. T. Arita. 1998. Nearctic limits in middle America as determined by distributions of bats. Journal of Mammalogy, 79:772-781.

Owen, R. D. 1987. Phylogenetic analyses of the bat Subfamily Stenodermatinae (Mammalia: Chiroptera). Special Publications The Museum, Texas Tech University, 26:1-65.

Pacheco, J., G. Ceballos y R. List. 2000. Los mamíferos de la región de Janos-Casas Grandes, Chihuahua, México. Revista Mexicana de Mastozoología, 4:71-85.

Pacheco, J., G. Ceballos y R. List. 2002. Reintroducción del hurón de patas negras en las praderas de Janos, Chihuahua. Biodiversitas, 42:1-5.

Patterson, B. D. 2001. Fathoming tropical biodiversity: the continuing discovery of Neotropical mammals. Diversity and Distribution, 7:191-196.

Peppers, L. L., D. S. Carroll y R. D. Bradley. 2002. Molecular systematics of the genus Sigmodon (Rodentia: Muridae): evidence from the mitochondrial cytochrome- $b$ gene. Journal of Mammalogy, 83:396-407.

Peters, S. L., B. K. Lim y M. D. Engstrom. 2002. Systematics of dog-faced bats (Cynomys) based on molecular and morphometric data. Journal of Mammalogy, 83:1097-1110.

Piaggio, A. y G. S Spicer. 2001. Molecular phylogeny of the chipmunks inferred from mitochondrial cytochrome $b$ and cytochrome ozidase II gene sequences. Molecular Phylogeny and Evolution, 20:335-350.

Piaggio, A. J., E. W. Valdez, M. A. Bogan y G. S Spicer. 2002. Systematics of Myotis occultus (Chiroptera: Vespertilionidae) inferred from sequences of two mitochondrial genes. Journal of Mammalogy, 83:386-395.

Ramamoorthy, T. P., R. Bye, A. Lot y J. Fa (eds.). 1993. Biological Diversity of Mexico. Origins and Distribution. Oxford University Press, New York.

Ramírez-Pulido, J., J. Arroyo-Cabrales y A. Castro-Campillo. 2005. Estado actual y relación nomenclatural de los mamíferos terrestres de México. Acta Zoológica Mexicana (nueva serie), 21:21-82.

Ramírez- Pulido, J., M. C. Britton, A. Perdomo y A. Castro. 1986. Guía de los mamíferos de México, referencias hasta 1983. Universidad Autónoma Metropolitana, Unidad Iztapalapa. México, D.F.

Ramírez-Pulido, J., R. López-W., C. Müdespacher y I. Lira. 1983. Catálogo de los mamíferos terrestres nativos de México. Editorial Trillas, México D.F.

Ramírez-Pulido, J. y C. Müdespacher. 1987. Estado actual y perspectivas del conocimiento de los mamíferos de México. Ciencia, 38:49-67.

Ramírez- Pulido, J., A. Castro-Campillo, J. Arroyo-Cabrales y F. A. Cervantes. 1996. Lista taxonómica de los mamíferos de México. Occasional Papers, The Museum, Texas Tech University, 158:1-62.

Riddle, B.R., D.J. Hafner y L.F. Alexander. 2000a. Comparative phylogeography of Baileys’ pocket mouse (Chaetodipus baileyi) and the Peromyscus eremicus species group: historical vicariance of the Baja California Peninsular desert. Molecular Phylogenetics and Evolution, 17:161-172.

Riddle, B.R., D.J. Hafner y L.F. Alexander. 2000b. Phylogeography and systematics of Peromyscus eremicus species group and historical biogeography of North American warm regional deserts. Molecular Phylogenetics and Evolution, 17:145-160. 
Robles Gil, P., G. Ceballos y F. Eccardi. 1993. Diversidad de fauna mexicana. CEMEX, Monterrey, Mexico.

Rodríguez-Jaramillo, M. del C. y D. Gendron. 1996. Report of a sea otter, Enhydra lutris, off the coast of Isla Magdalena, Baja California Sur, México. Marine Mammal Science, 12:153156.

Romo-Vázquez, E., León-Paniagua, L. y Sánchez, O. 2005. A new species of Habromys (Rodentia: Neotominae) from México. Proceedings of the Biological Society of Washington 118(3):605-618.

Ruedas, L. A. 1998. Systematics of Sylvilagus Gray, 1867 (Lagomoprpha: Leporidae) from southwestern North America. Journal of Mammalogy, 79:1355-1378.

Salinas, M. y P. Ladrón de Guevara. 1993. Riqueza y diversidad de los mamíferos marinos. Pp. 85 -93, en: Biología y problemática de los vertebrados en México (O. Flores-V. y A. Navarro-S., eds.). Ciencias, número especial, 7:1-110.

Sánchez-H., C. 1986. Noteworthy records of bats from islands in the Gulf of California. Journal of Mammalogy, 67:212-213.

Secretaría de Medio Ambiente, Recursos Naturales y Pesca (SEMARNAP). 2002. Norma Oficial Mexicana NOM-059-ECOL-2000. Protección ambiental, especies de flora y fauna silvestres de México, categorías de riesgo y especificaciones para su inclusión, exclusión o cambio, y lista de especies en riesgo. Diario Oficial de la Federación, Lunes 16 de octubre de 2001, 1:1-62.

Simmons, N. B. 1996. A new species of Micronycteris (Chiroptera: Phyllostomidae) from northeastern Brazil, with comments on phylogenetic relationships. American Museum Novitates, 3158:1-34.

Simmons, N. B. 1998. 1. A reappraisal of interfamilial relationships of bats. Pp. 3-26, en: Bat Biology and Conservation (T. H. Kunz y P. A. Racey, eds.). Smithsonian Institution Press, Washington, D.C.

Simmons, N. B. 2005. Chiroptera. Pp. 401, en: Mammal Species of the World, a taxonomic and geographic reference. (Wilson. D. E. y D. M. Reeder, eds.). 3rd ed. Smithsonian Institution Press, Washington, D. C.

Simmons, N. B. y C. O. Handley, Jr. 1998. A revisión of Centronycteris Gray (Chiroptera: Emballonuridae) with notes on natural history. American Museum Novitates, 3239:1-28.

Smith, F. A., B. T. Bestelmeyer, J. Biardi y M. Strong. 1993. Anthropogenic extinction of the endemic woodrat, Neotoma bunkeri Burt. Biodiversity Letters, 1:149-155.

Tejedor, A. 2005. A new species of funnel-eared bat (Natalidae: Natalus) from Mexico. Journal of Mammalogy, 86:1109-1120.

Torres, A., C. Esquivel y G. Ceballos. 1995. Diversidad y conservación de los mamíferos marinos de México. Revista Mexicana de Mastozoología, 1:22-43.

Urbán-R., J. y D. Aurioles-G. 1992. First record of the pygmy beaked whale Mesoplodon peruvianus in the North Pacific. Marine Mammal Science, 8:420-425.

Van Den Bussche, R. A., J. L. Hudgeons y R. J. Baker. 1998. Phylogenetic accuracy, stability, and congruence: relationships within and among the New World bat genera Artibeus, Dermanura, and Koopmania. Pp. 59-71, en: Bat Biology and Conservation (T. H. Kunz y P. A. Racey, eds.). Smithsonian Institution Press, Washington. 
Villa-R., B., J. P. Gallo y B. Le Boeuf. 1986. La foca monje Monachus tropicalis (Mammalia: Pinnipedia) definitivamente extinguida en México. Anales del Instituto de Biología, Universidad Nacional Autónoma de México, Serie Zoología, 56:573-588.

Voss, R. S., y S. A. Jansa. 2003. Phylogenetic studies on Didelphid marsupials ii. nonmolecular data and new irbp sequences: separate and combined analyses of didelphine relationships with denser taxon sampling. Bulletin of the American Museum of Natural History, 276:182.

Wang, H. G., R. D. Owen, C. Sánchez-Hernández y M. de L. Romero-Almaraz. 2003. Ecological characterization of bat species distributions in Michoacán, México, using a geographic information system. Global Ecology \& Biogeography, 12:65-85.

Weber, M. 1995. La introducción del Jabalí europeo a la Reserva de la Biósfera La Michilía, Durango: implicaciones ecológicas y epidemiológicas. Revista Mexicana de Mastozoología, 1:69-73.

Wetterer, A. L., M. V. Rockman y N. B. Simmons. 2000. Phylogeny of phyllostomid bats (Mammalia: Chiroptera): data from diverse morphological systems, sex chromosomes, and restriction sites. Bulletin of the American Museum of Natural History, 248:1-200.

Williams, D. F., H. H. Genoways y J. K. Braun. 1993. Taxonomy. Pp. 38-196, en: Biology of the Heteromyidae (H. H. Genoways y J. H. Brown, eds.). The American Society of Mammalogists, Special Publication, 10:xii + 1-719.

Wilson, D. E. 1991. Mammals of the Tres Marías Islands. Bulletin of the American Museum of Natural History, 206:214-250.

Wilson. D. E. y D. M. Reeder (eds.). 1993. Mammal Species of the World, a taxonomic and geographic reference, 2nd ed. Smithsonian Institution Press, Washington, D. C.

Wilson. D. E. y D. M. Reeder (eds.). 2005 Mammal Species of the World, a taxonomic and geographic reference, 3rd ed. John Hopkins University Press, Baltimore.

Woodman, N. y R. M. Timm. 1999. Geographic variation and evolutionary relationships among broad-clawed shrews of the Cryptotis goldmani-group (Mammalia: Insectivora: Soricidae). Fieldiana, Zoology, New Series, 91:1-35.

Woodman, N. y R. M. Timm. 2000. Taxonomy and evolutionary relationships of Phillips' small-eared shrew, Cryptotis phillipsii (Schaldach, 1966), from Oaxaca, Mexico (Mammalia: Insectivora: Soricidae). Proceedings of the Biological Society of Washington, 113:339355.

Wright, D. B. 1989. Phylogenetic relationships of Catagonus wagneri: sister taxa from the Tertiary of North America. Pp. 281-308, en: Advances in Neotropical Mammalogy (K. H. Redford y J. F.Eisenberg, eds.). Sandhill Crane Press, Gainesville, Florida.

Yates, T. L. y J. Salazar-Bravo. 2005. A revision of Scapanus latimanus, with the revalidation of a species of Mexican mole. Pp. 489-505, en: Contribuciones Mastozoológicas en Homenaje a Bernardo Villa (V. Sánchez-Cordero y R. A. Medellín, eds.). Instituto de Biología e Instituto de Ecología, UNAM y Comisión Nacional para el Conocimiento y Uso de la Biodiversidad. México, D. F.

Zarza, H., R. A. Medellín y S. G. Pérez. 2003. First record of the Yucatan deer mouse, Peromyscus yucatanicus (Rodentia: Muridae) from Guatemala. The Southwestern Naturalist, 48:310-312. 
vol. 9

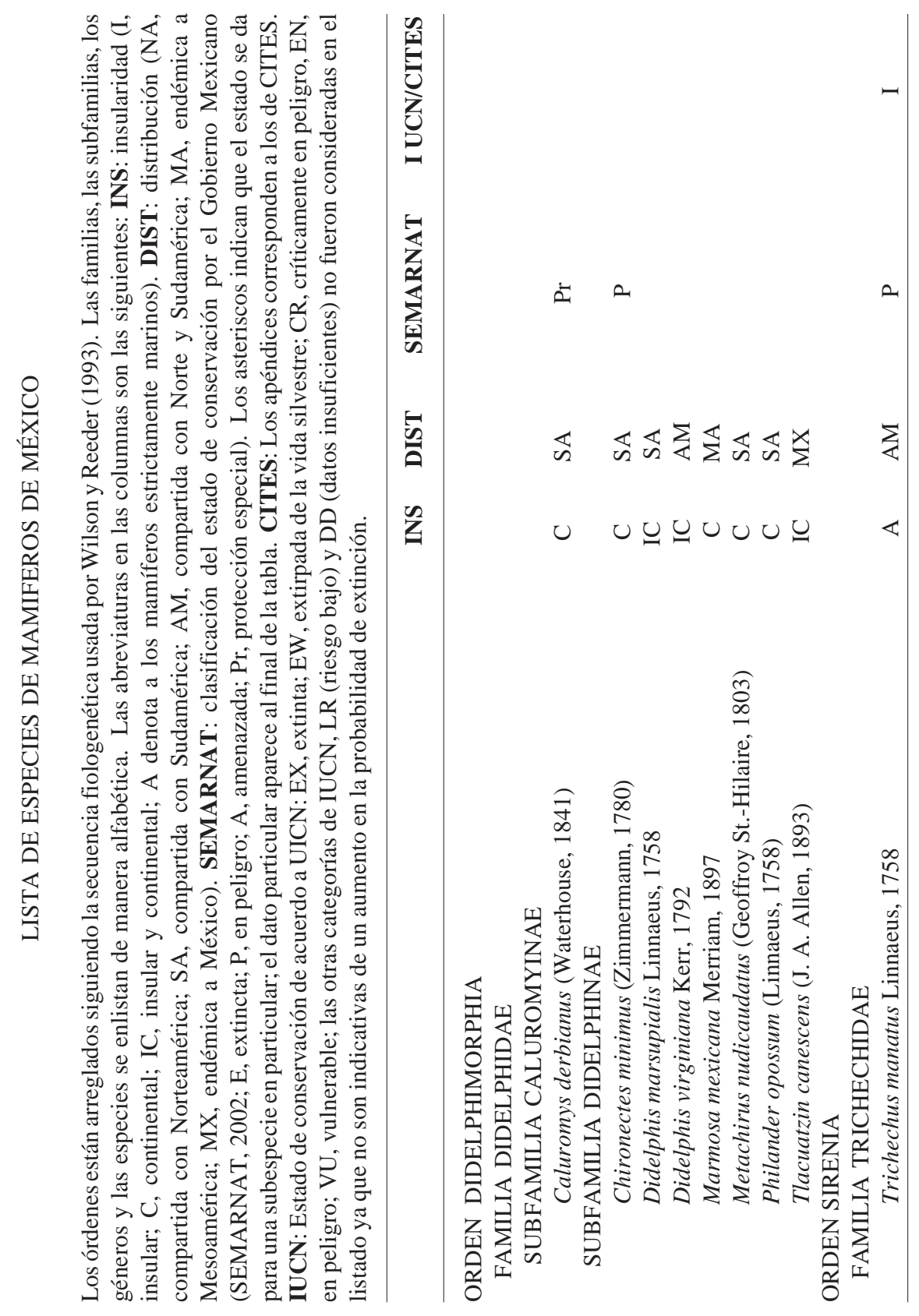




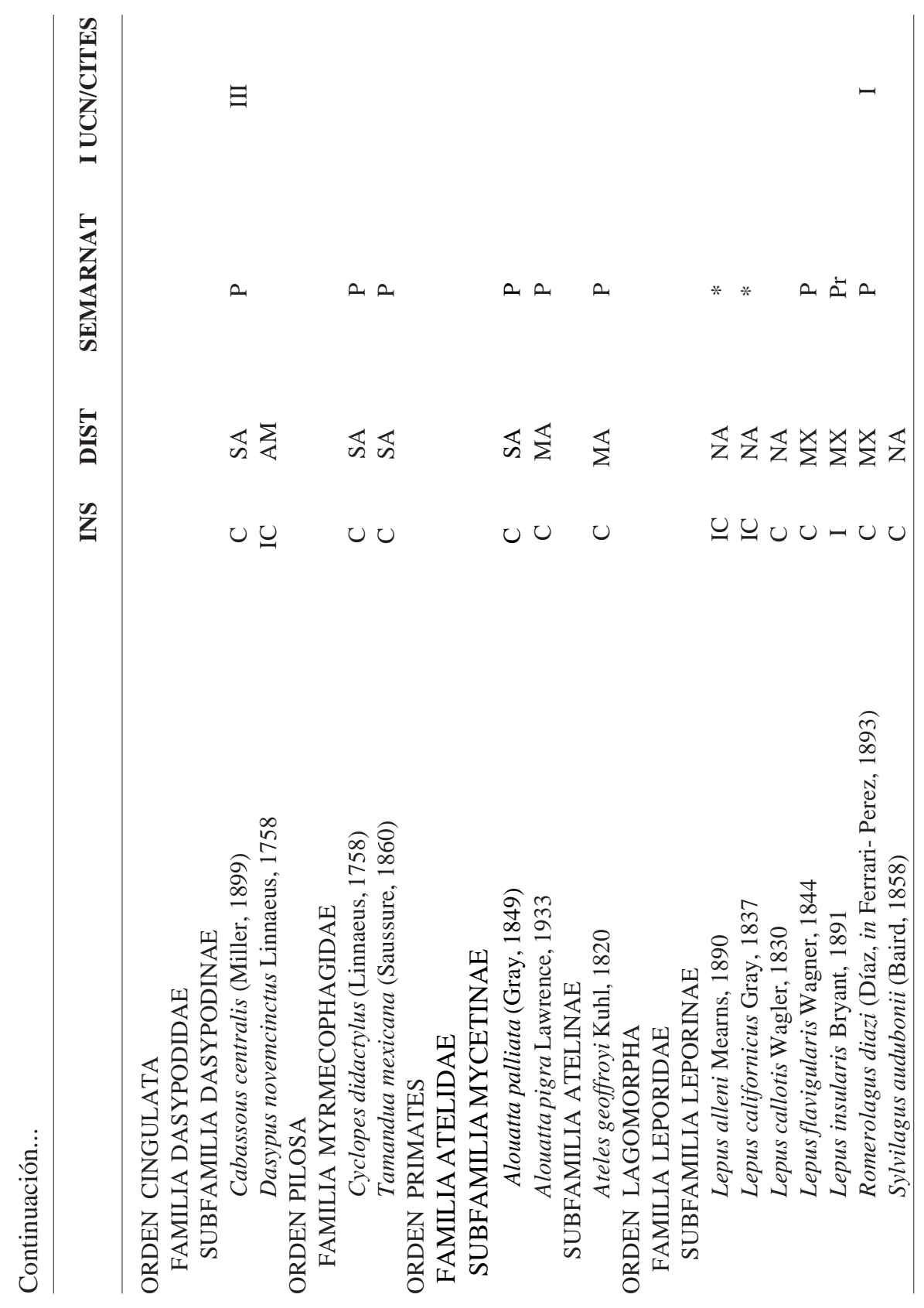




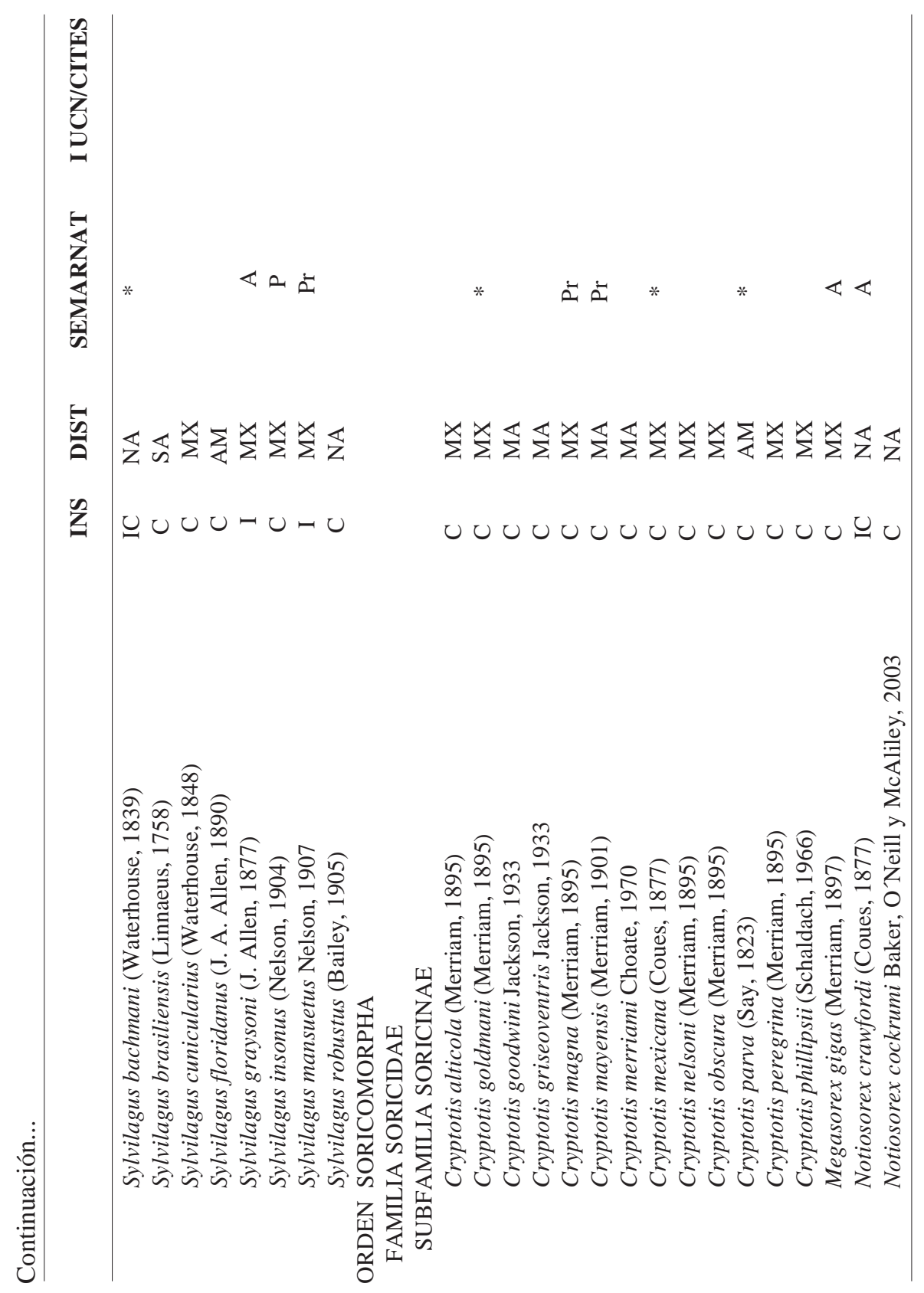




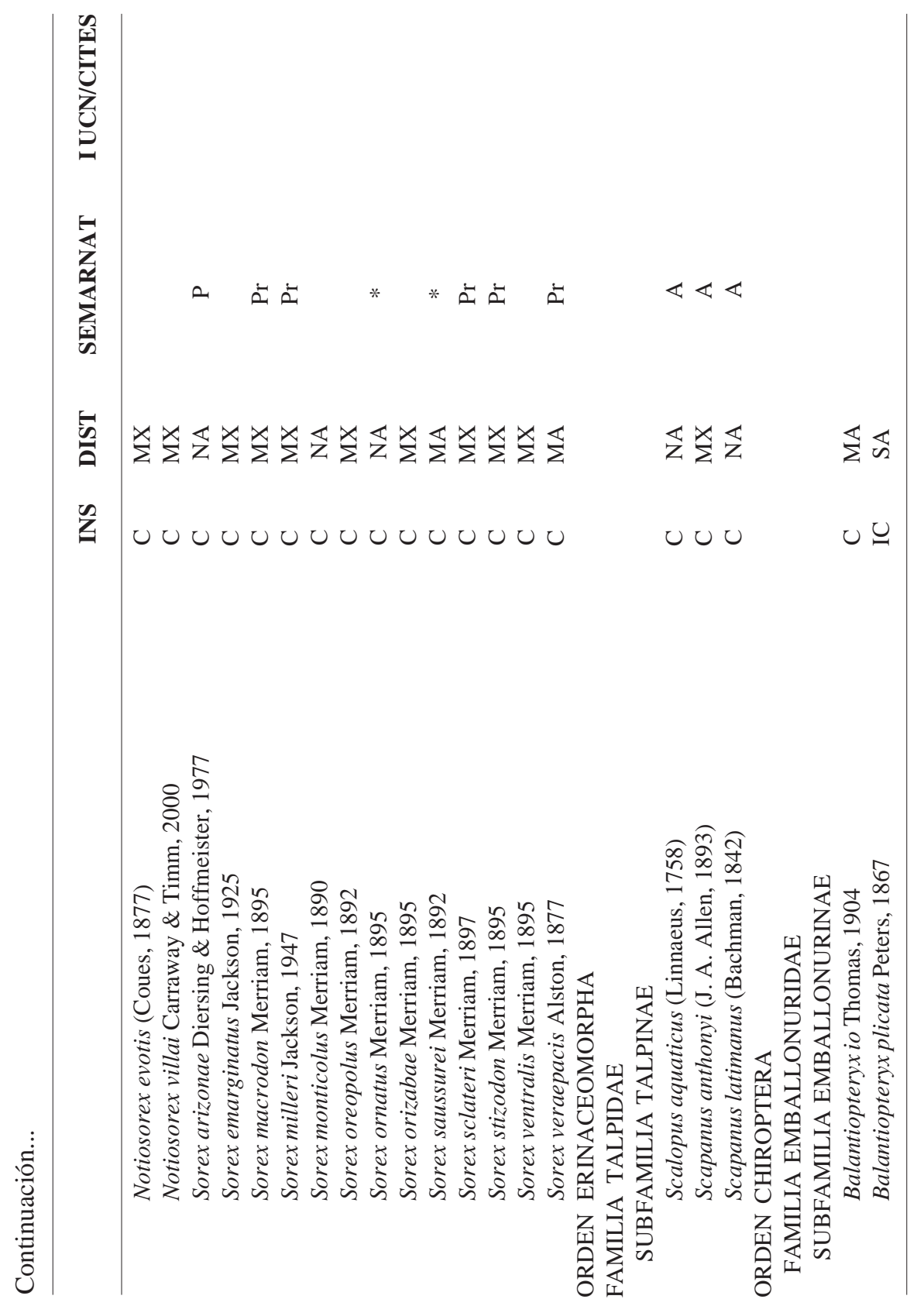




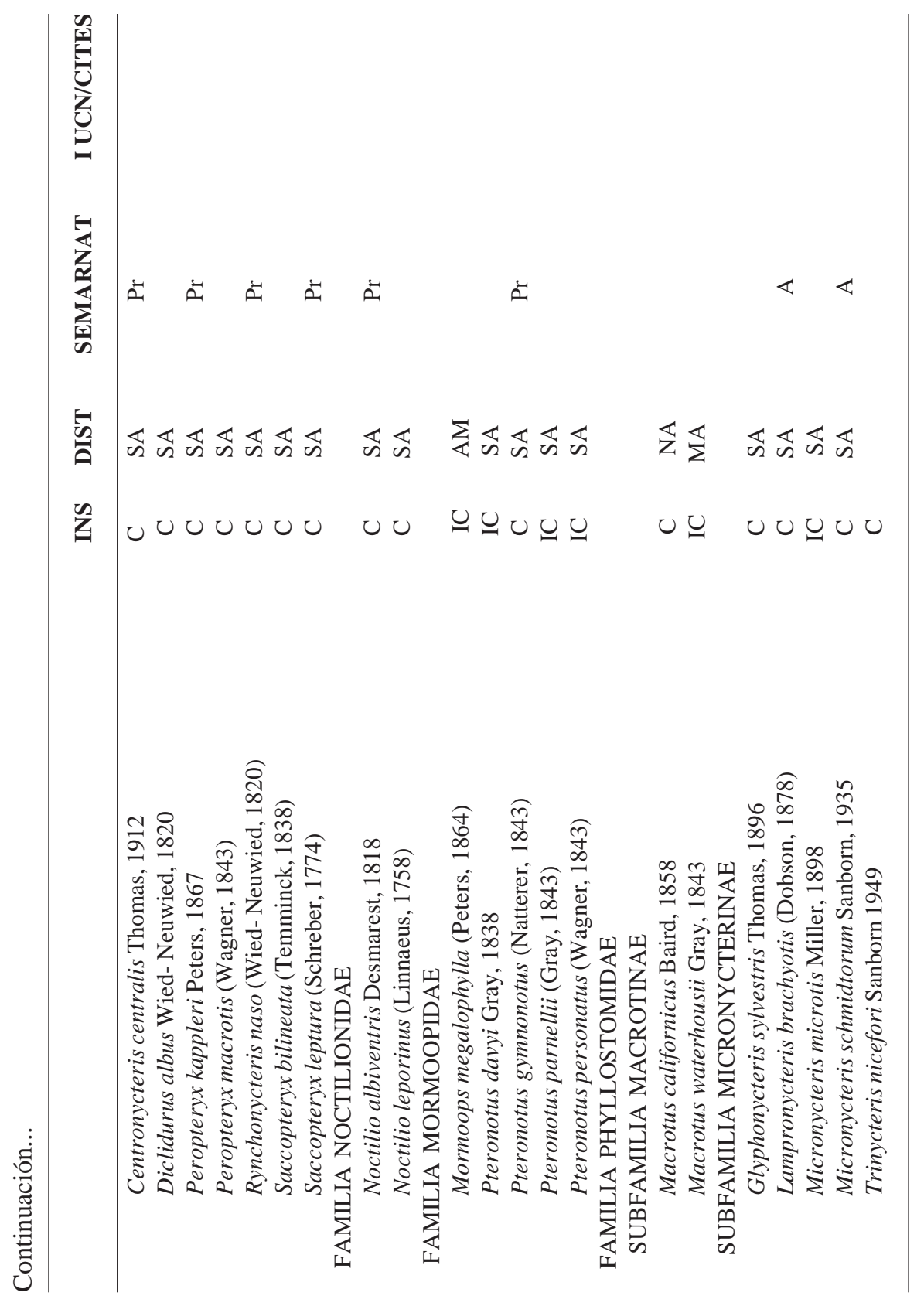




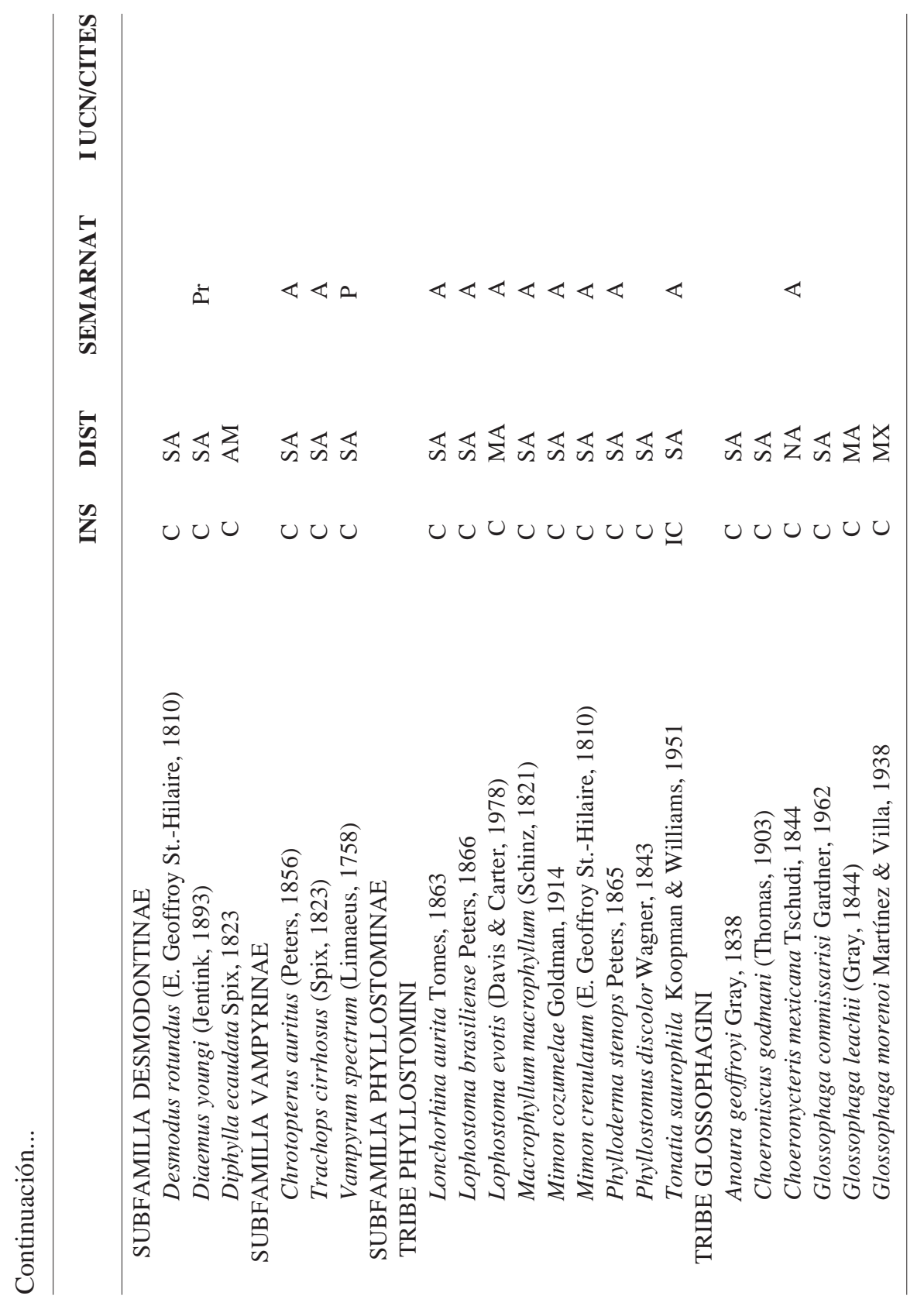




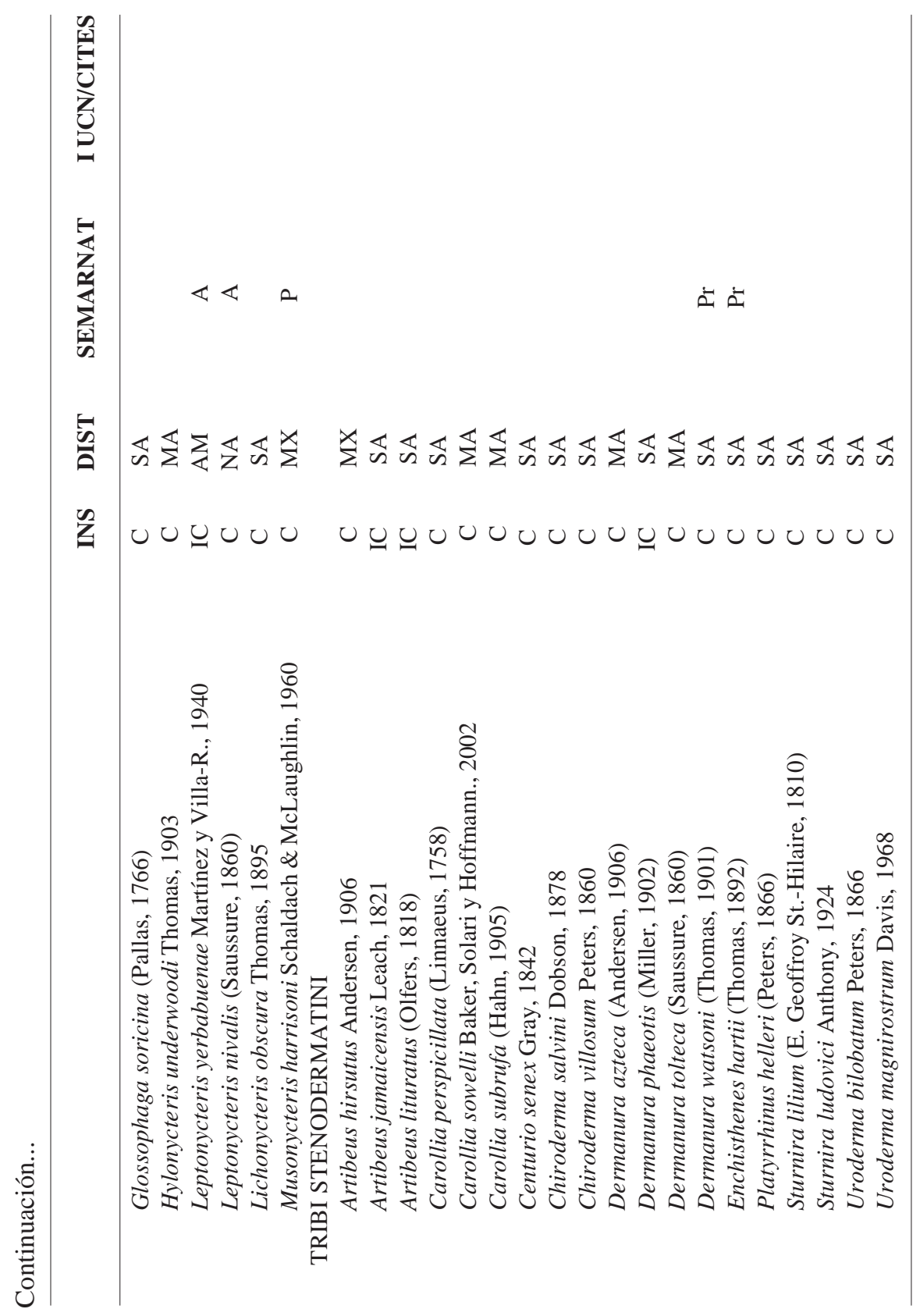




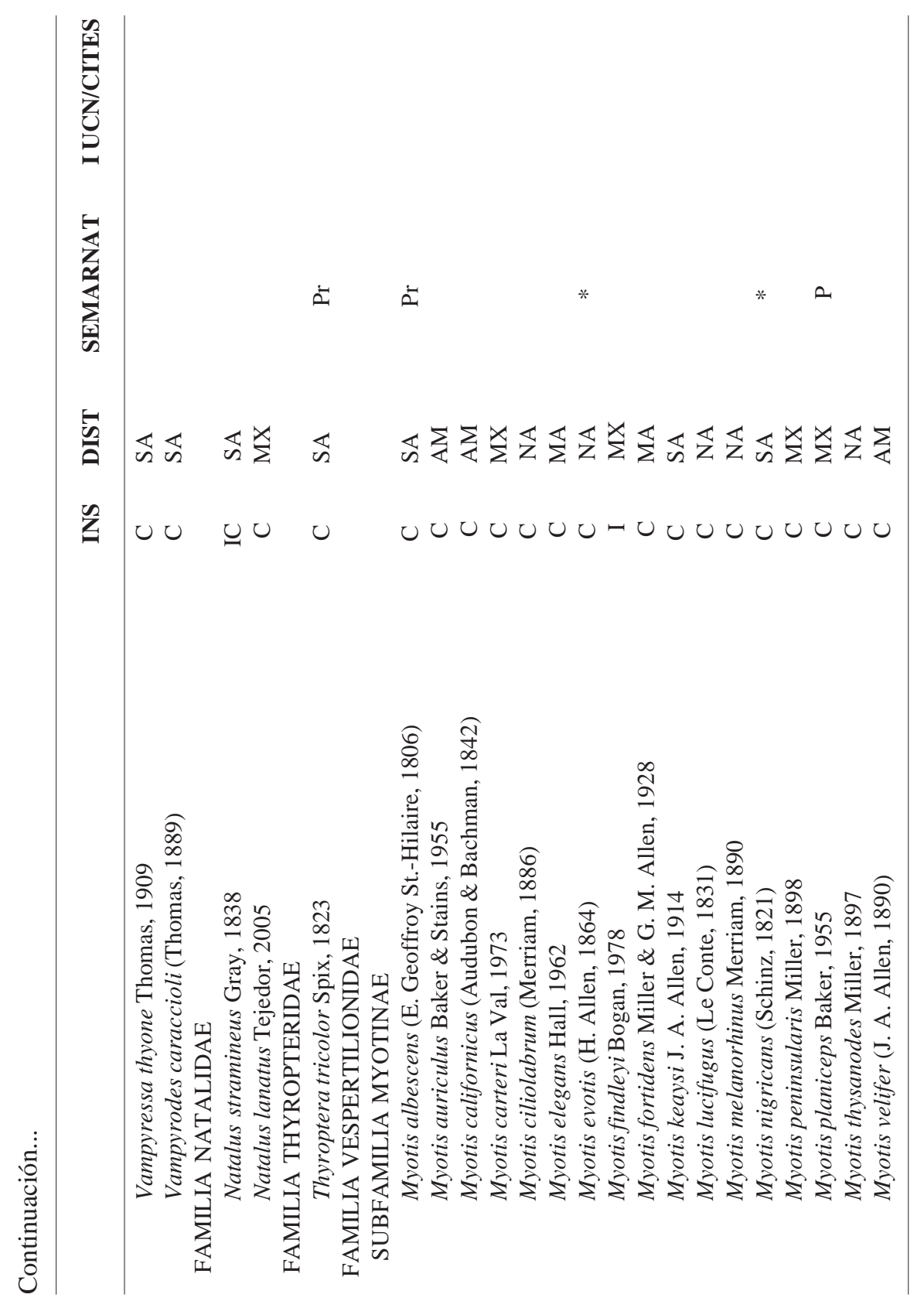




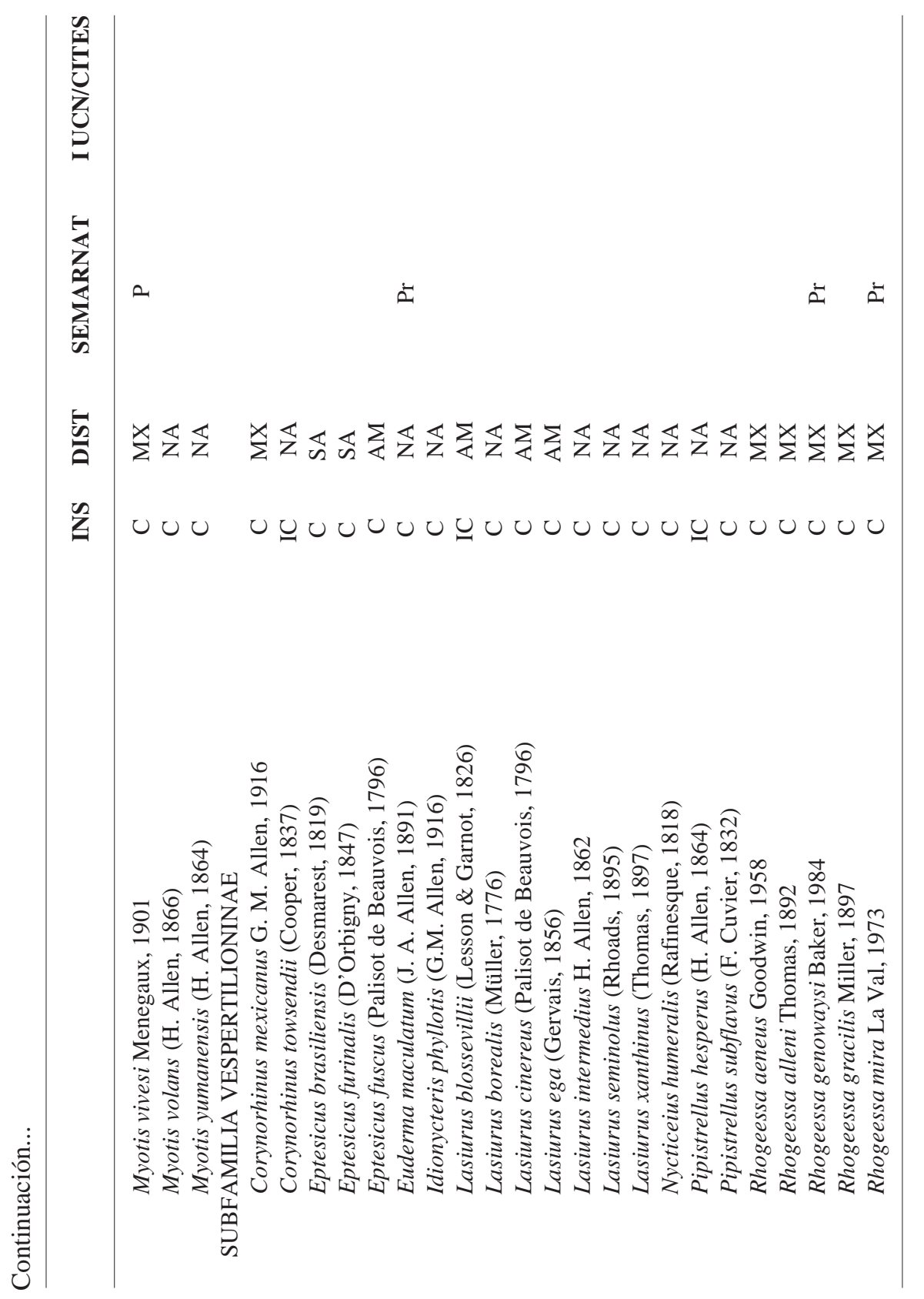




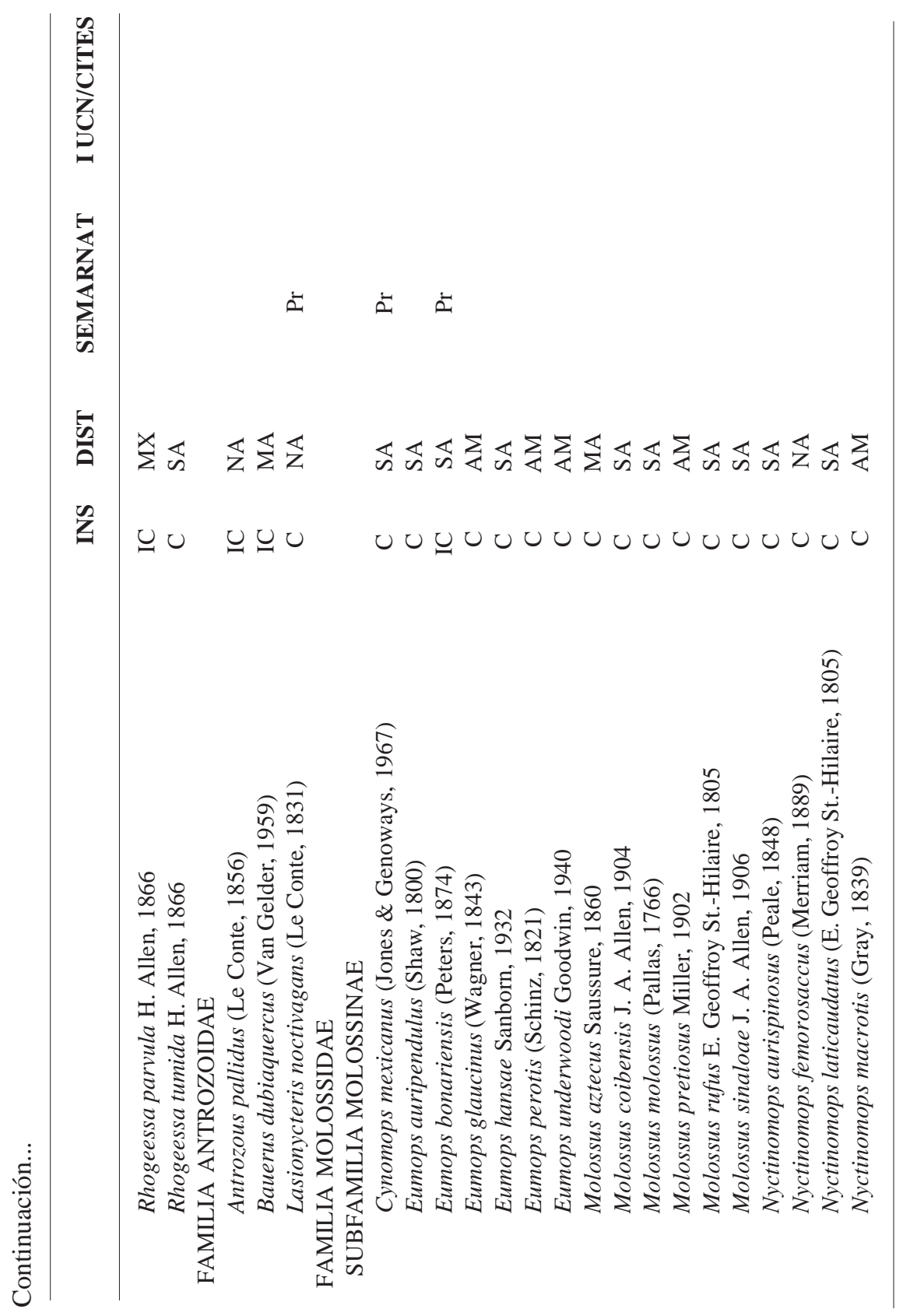




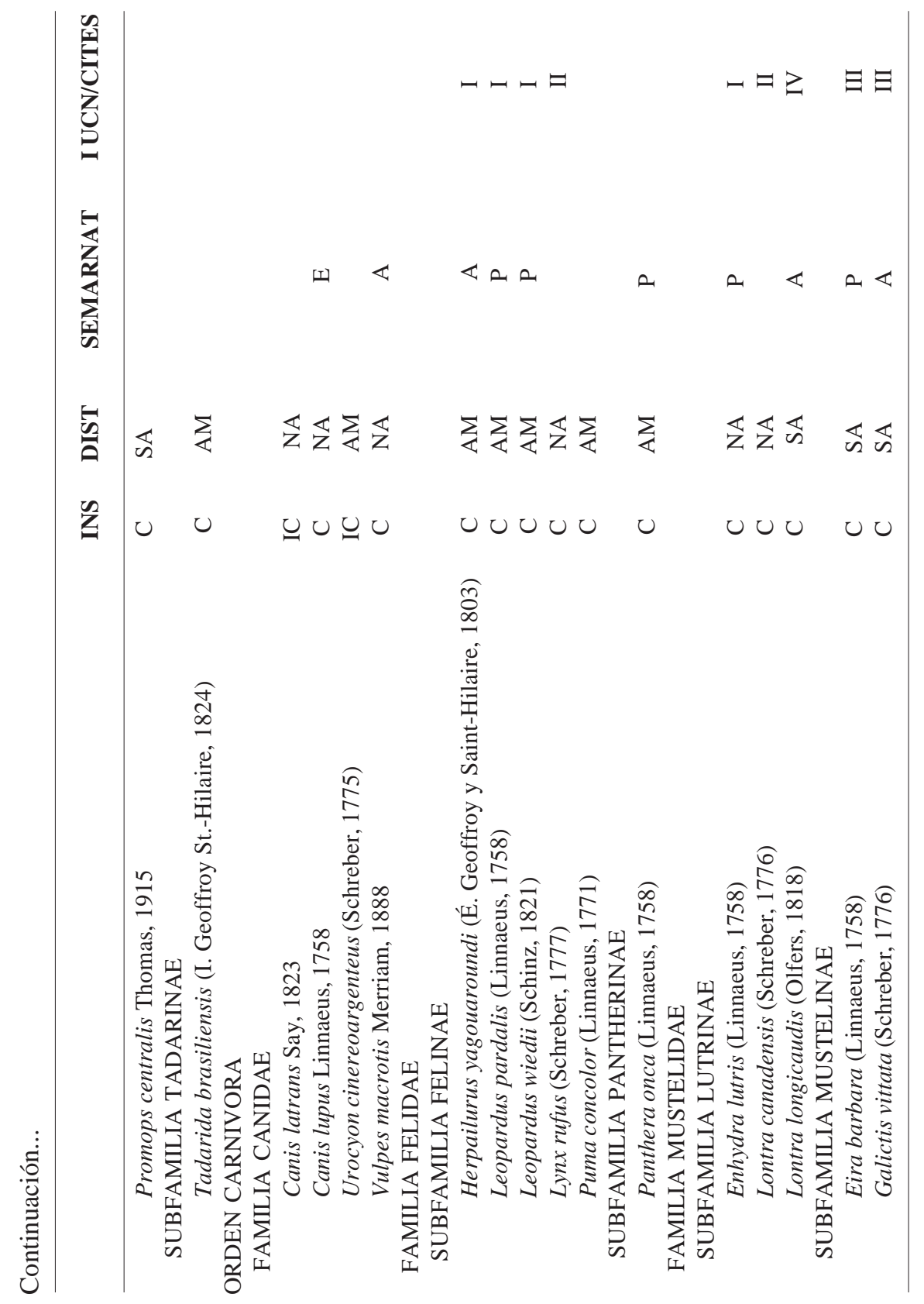




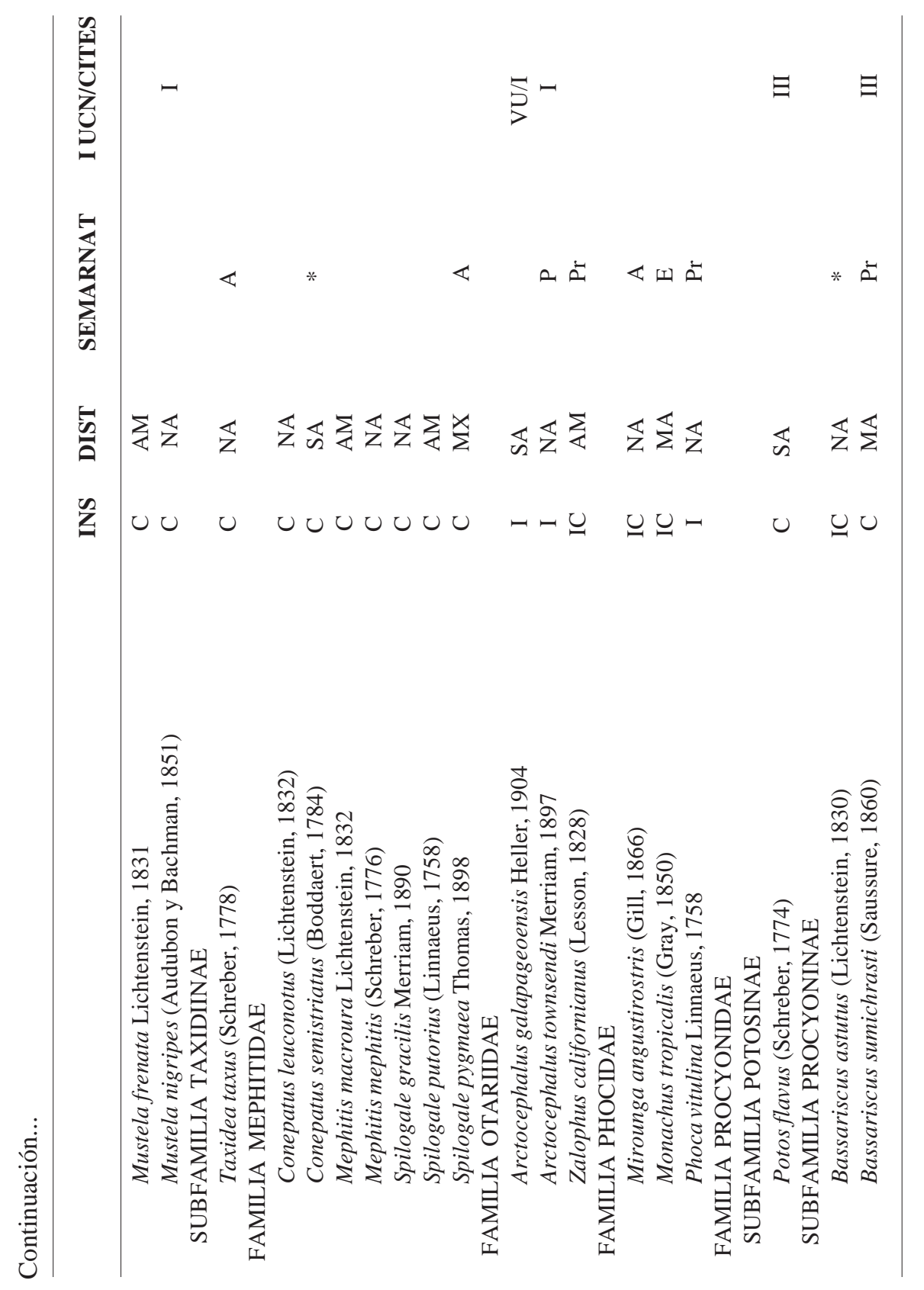




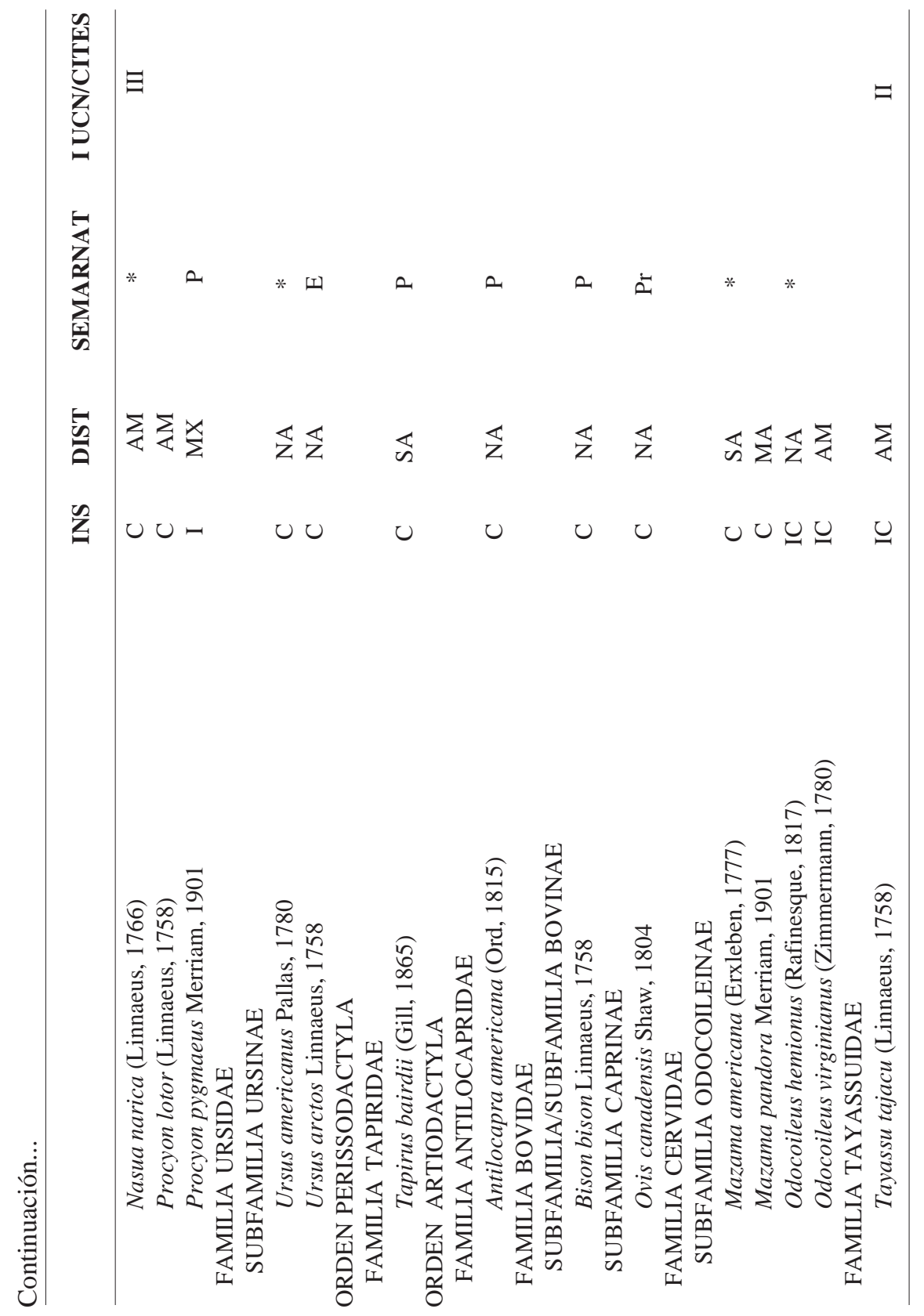




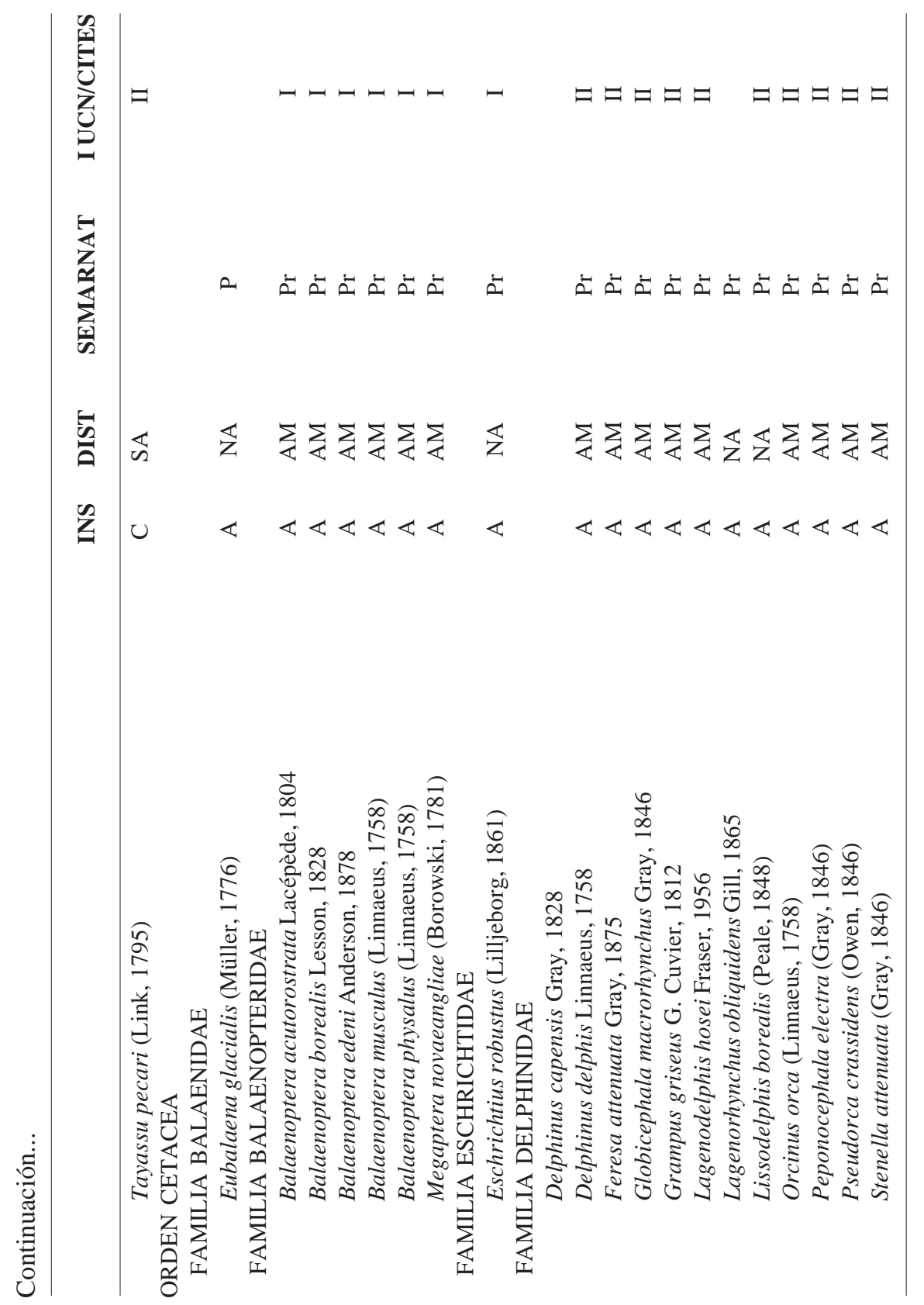




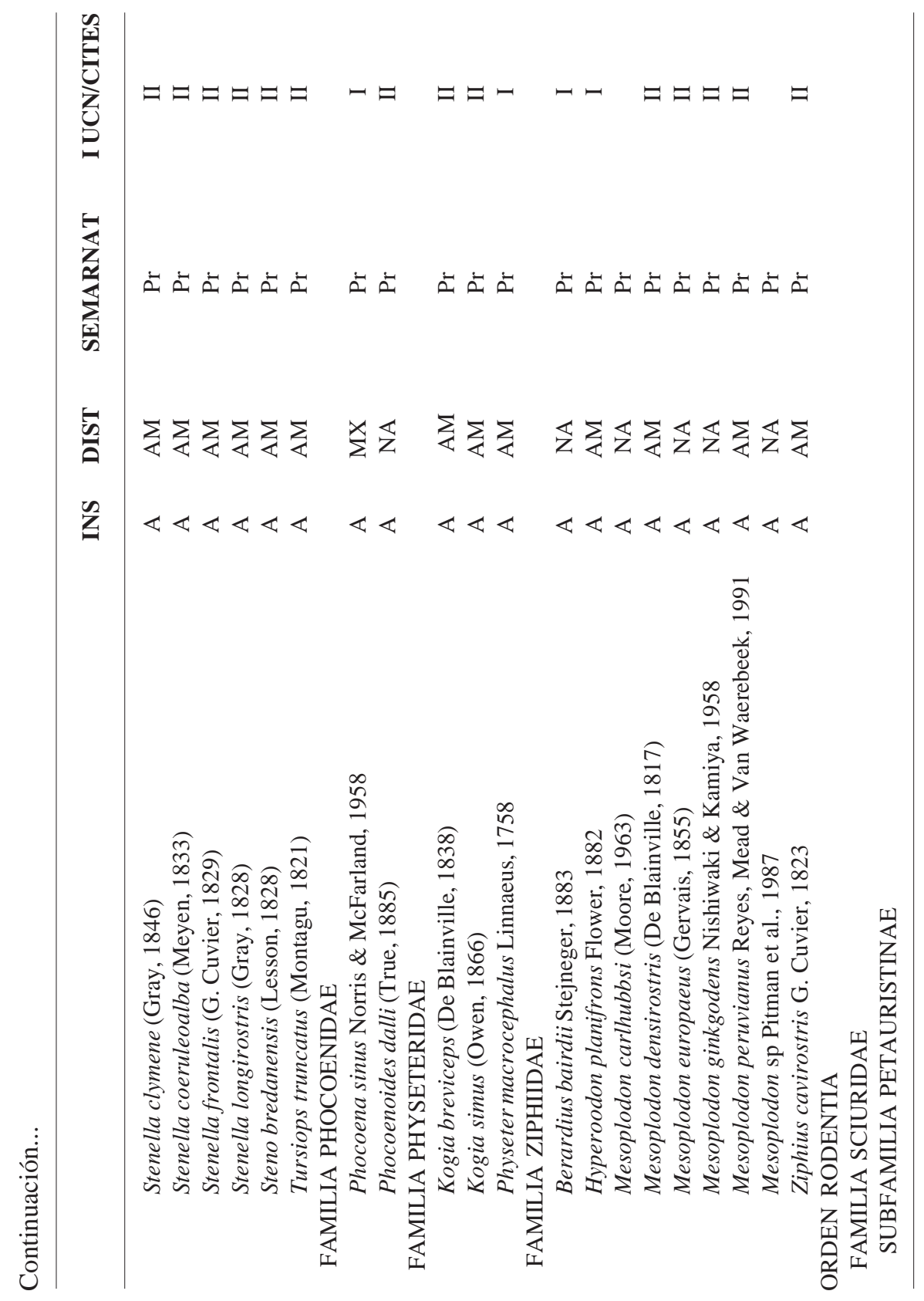




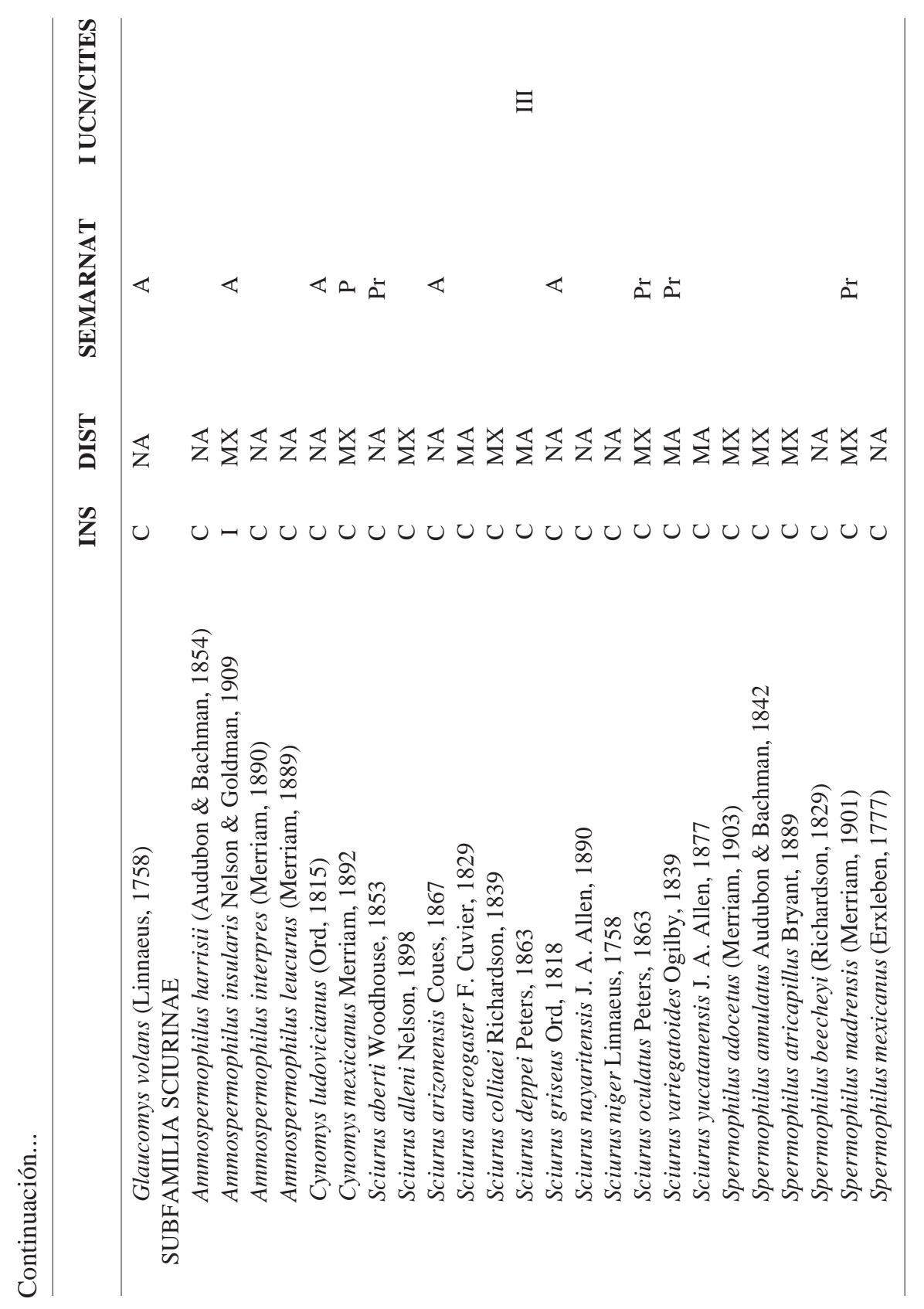




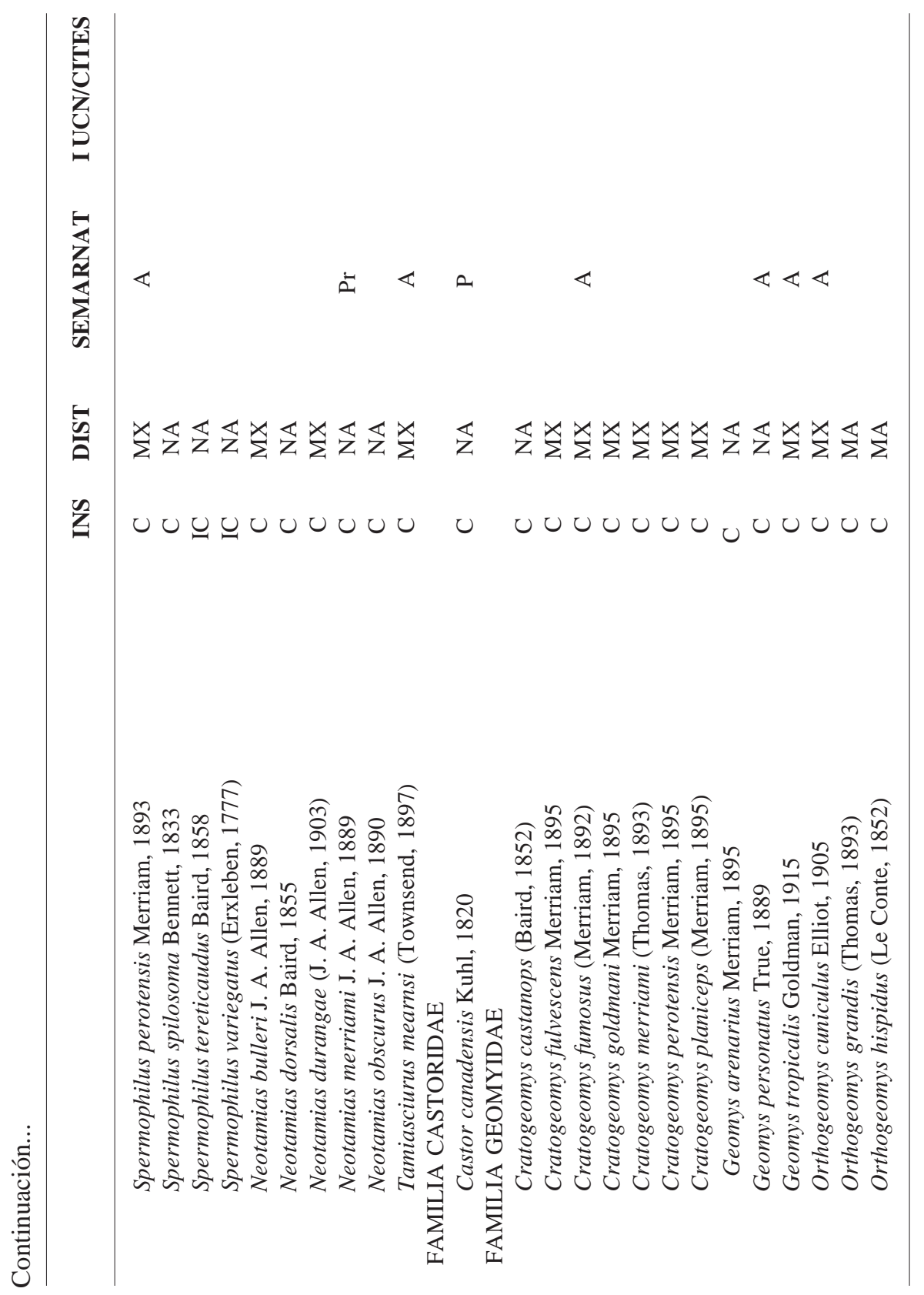




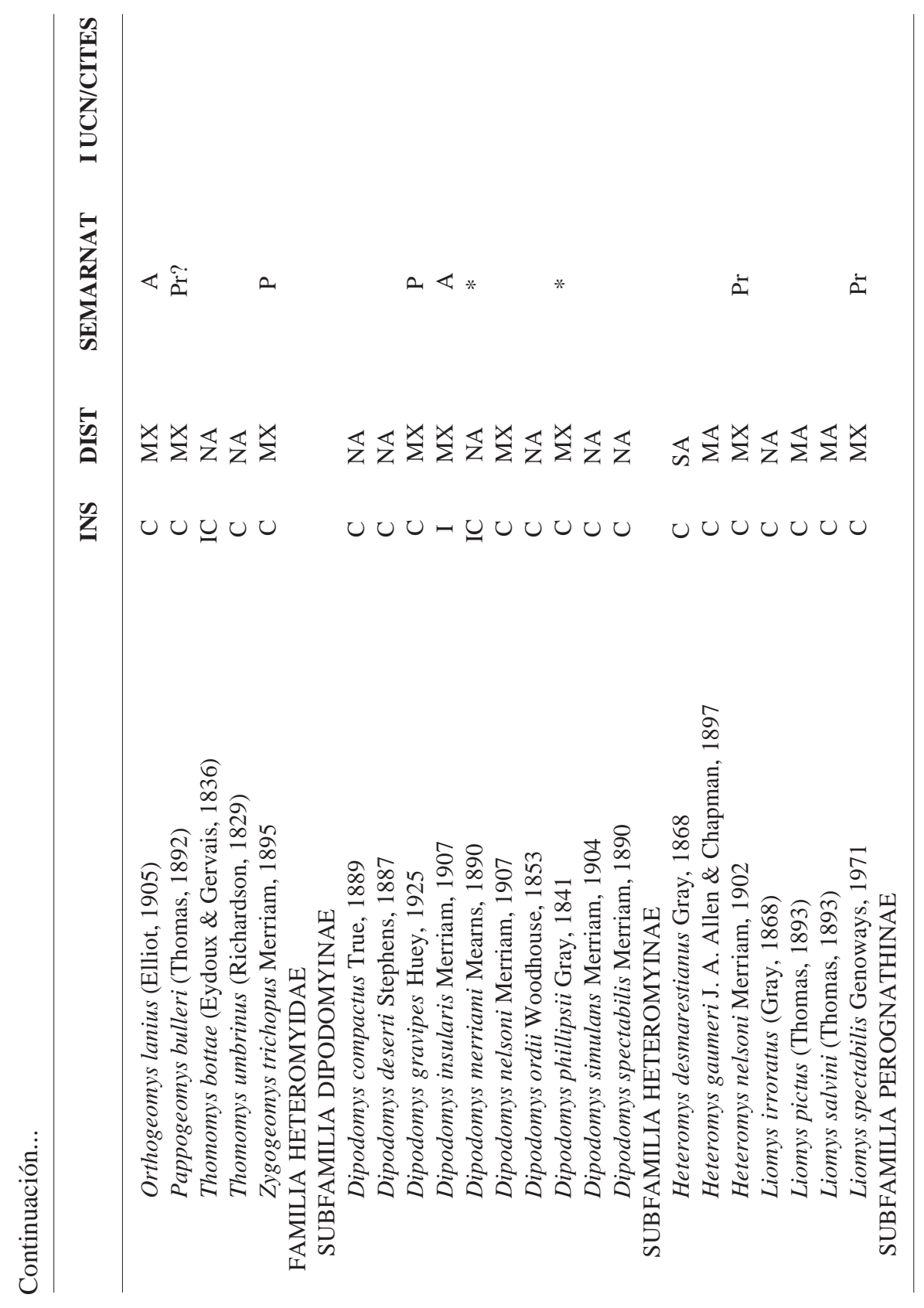




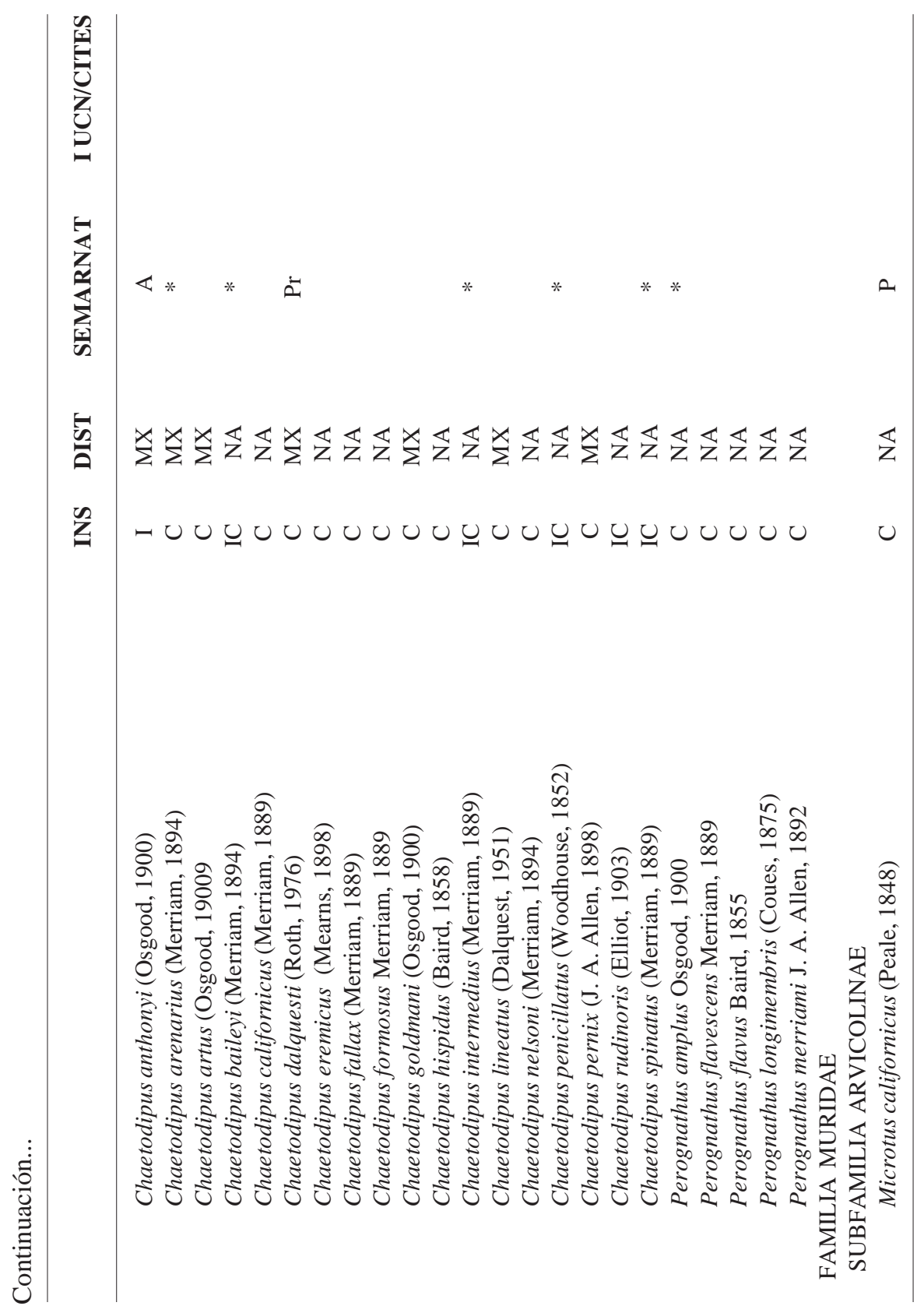




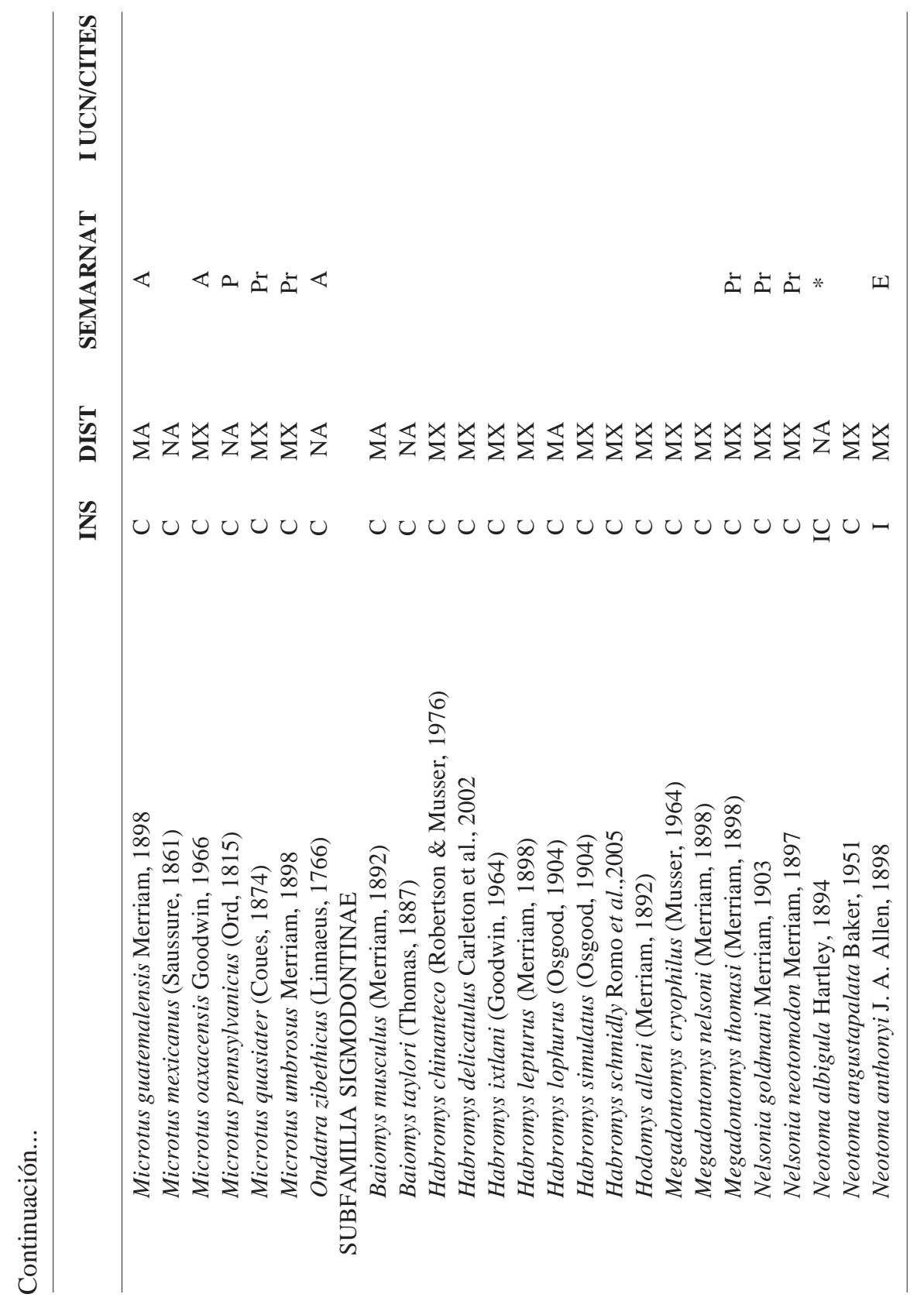




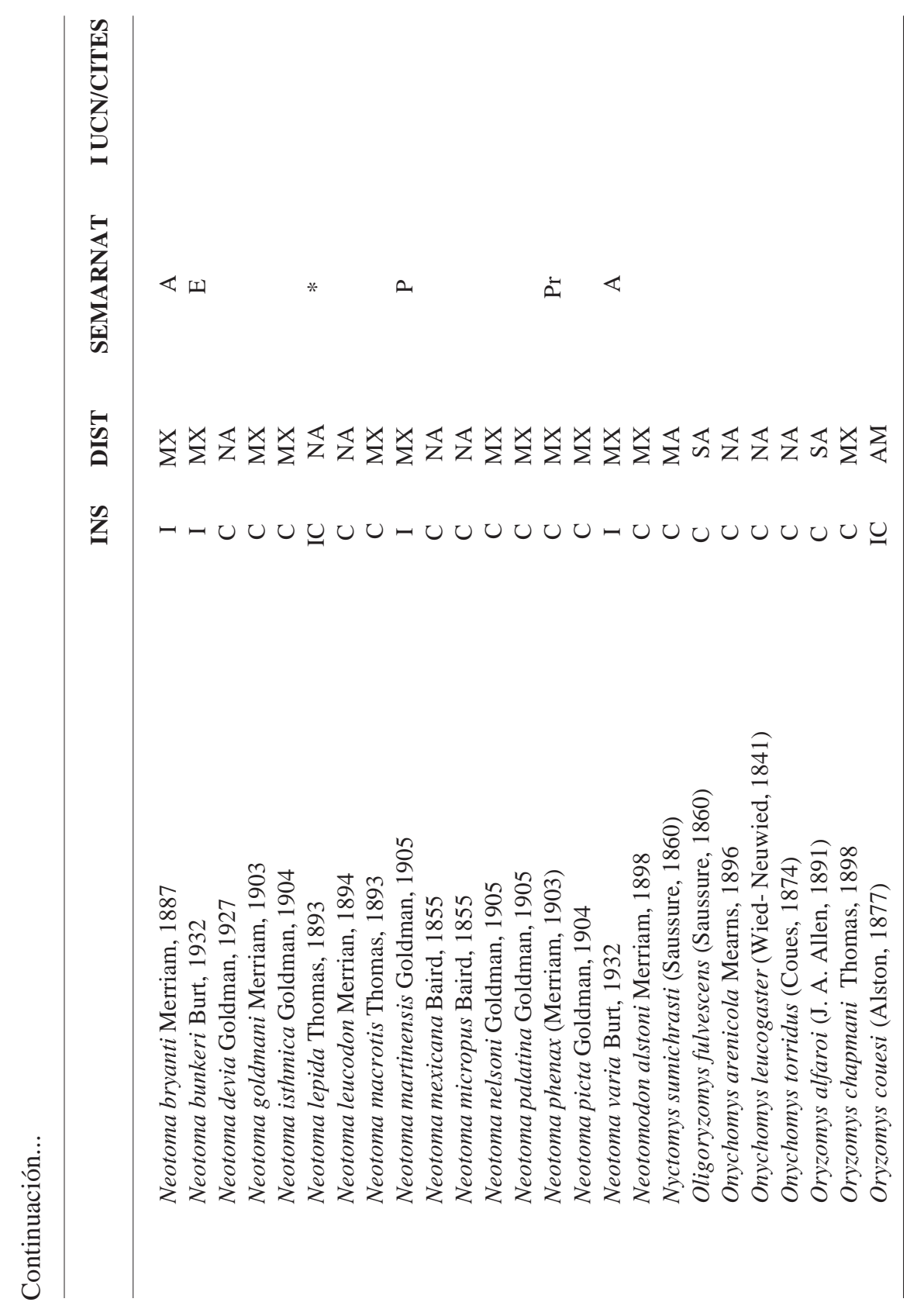




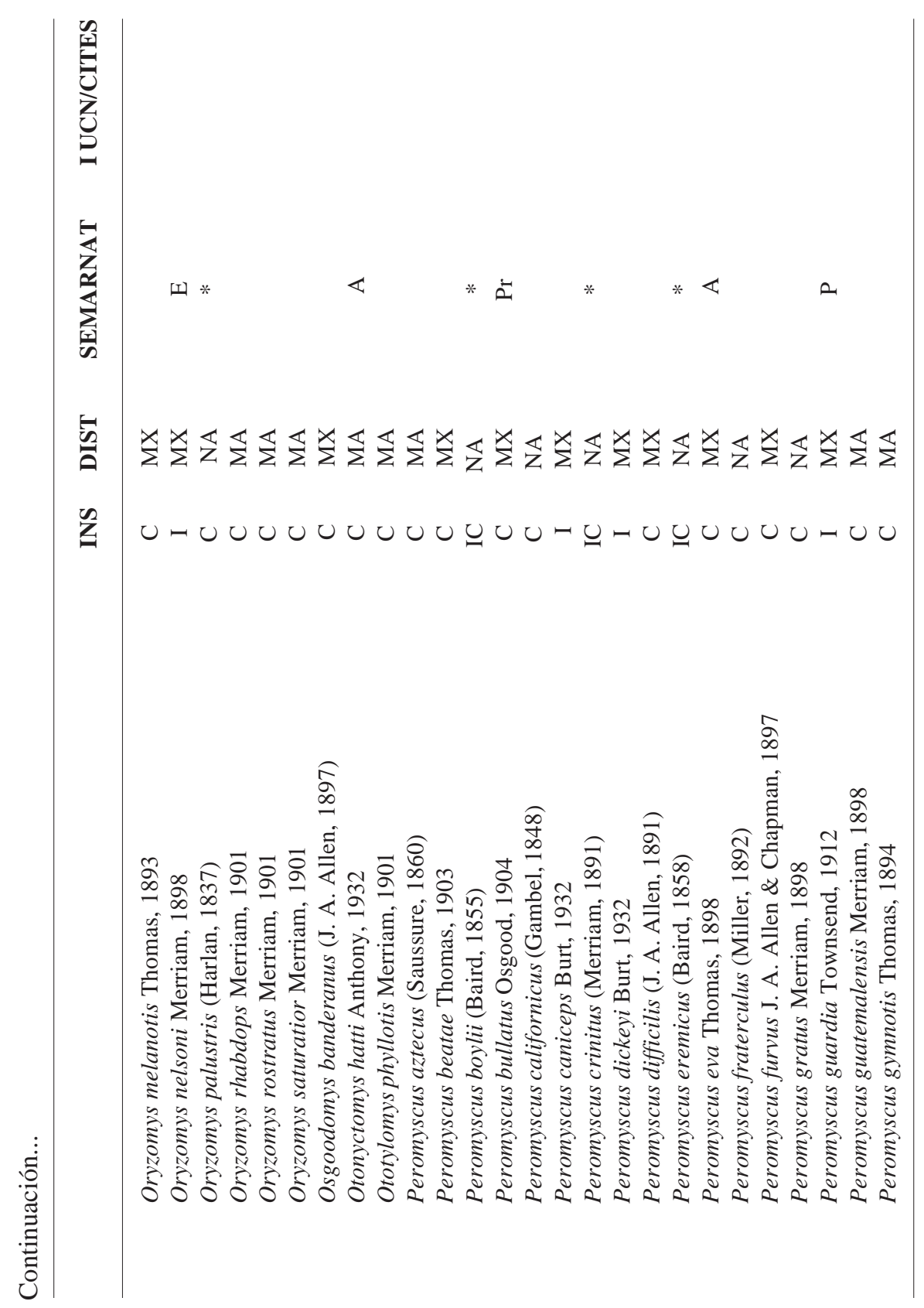




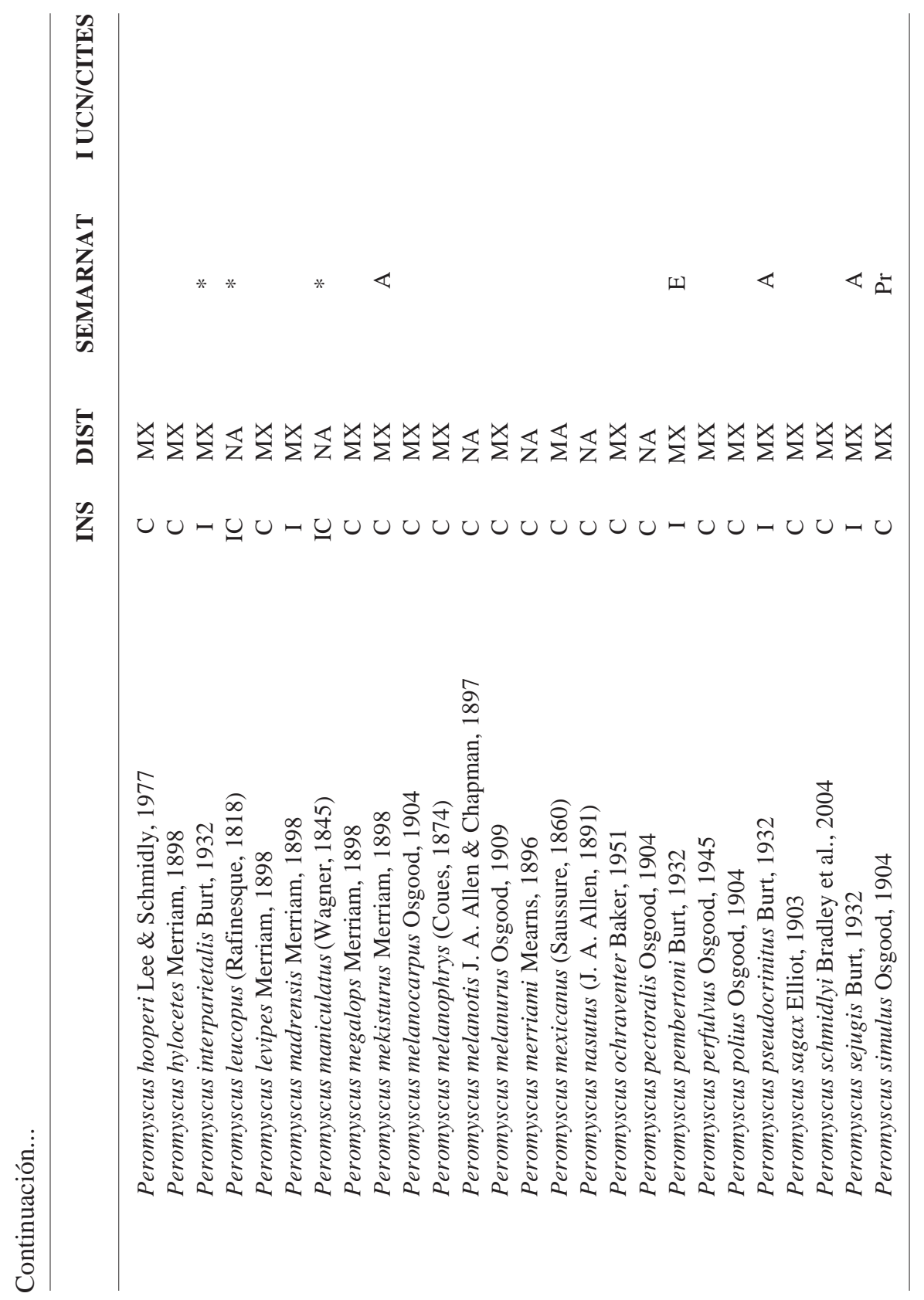




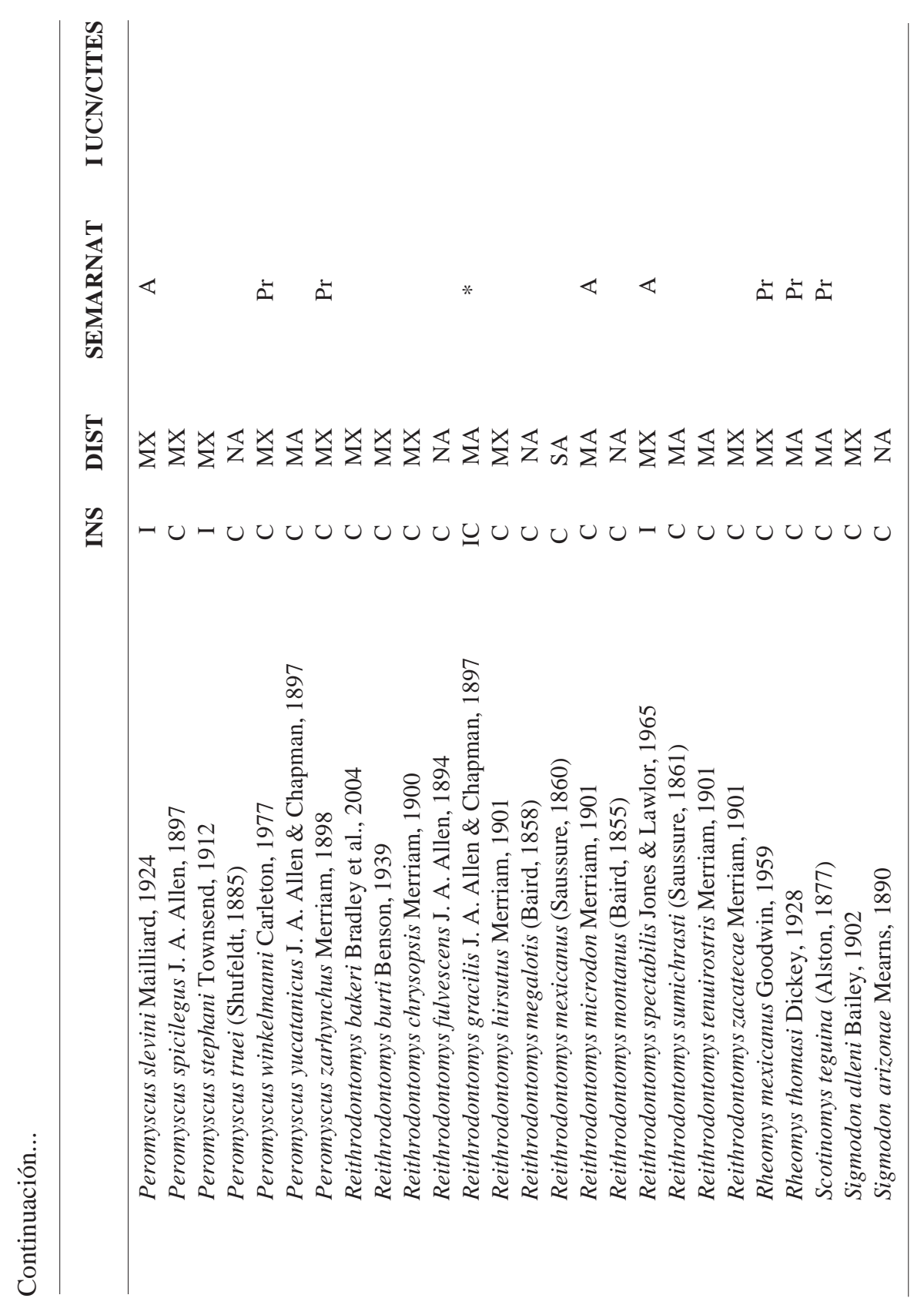


vol. 9

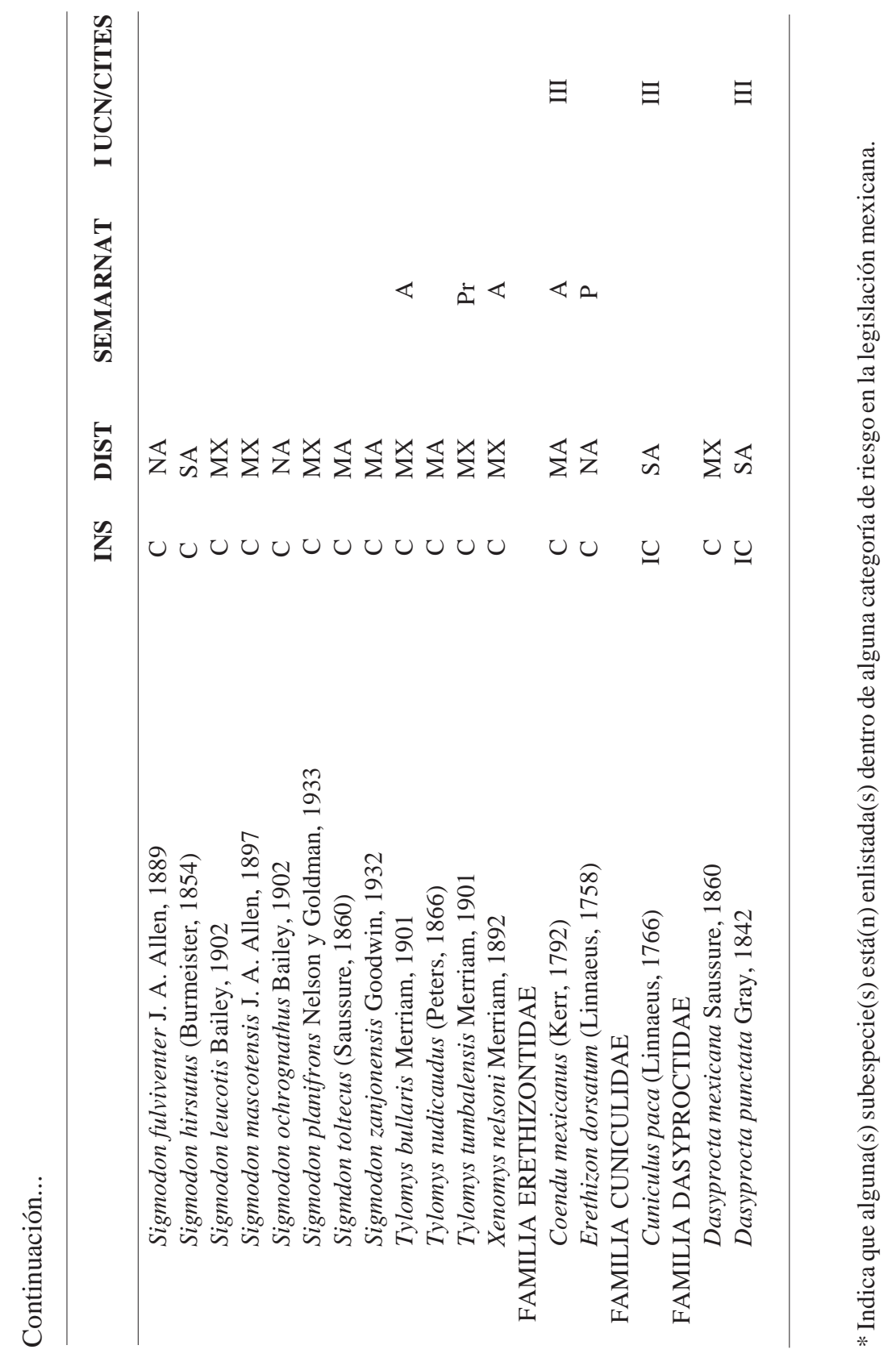




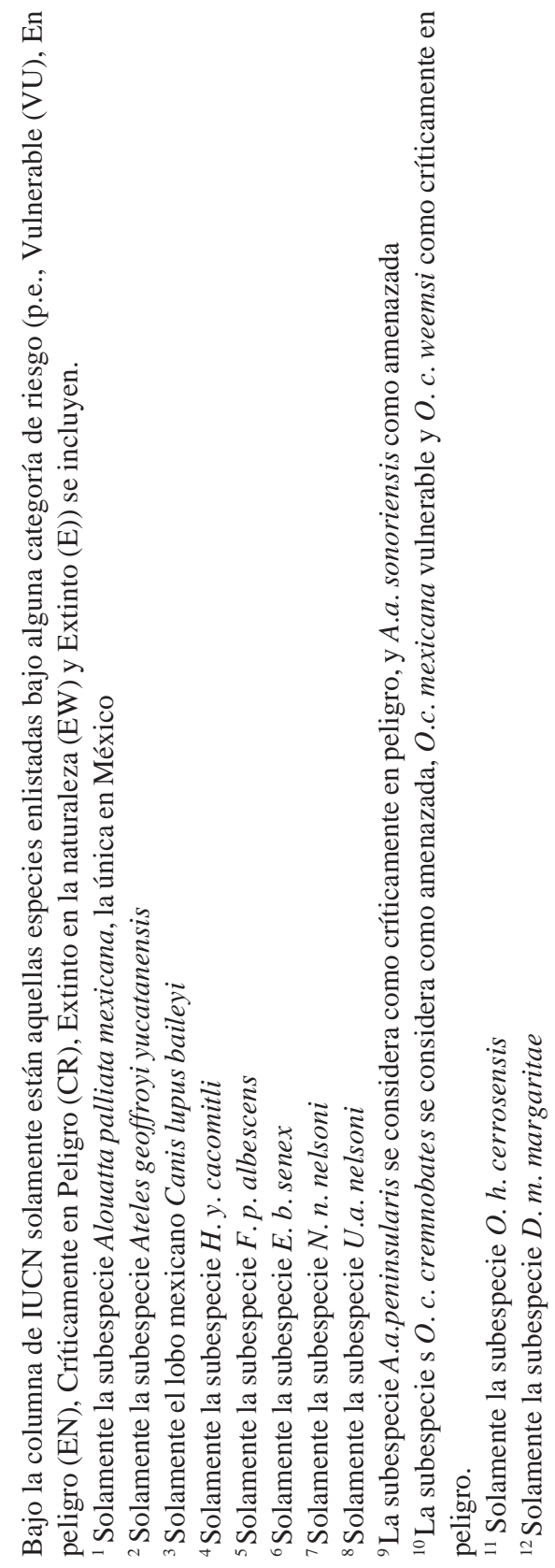

